\title{
Social Capital, Subjective Well-Being, and Happiness: Evidence from a Survey in Various European and Asian Countries to Address the Stiglitz Report
}

\author{
Shiori Tanaka, Koji Tokimatsu \\ Department of Transdisciplinary Science and Engineering, School of Environment and Society, Tokyo Institute of Technology, \\ Tokyo, Japan \\ Email: tanakashiori0609@gmail.com
}

How to cite this paper: Tanaka, S., \& Tokimatsu, K. (2020). Social Capital, Subjective Well-Being, and Happiness: Evidence from a Survey in Various European and Asian Countries to Address the Stiglitz Report. Modern Economy, 11, 322-348. https://doi.org/10.4236/me.2020.112026

Received: September 28, 2019

Accepted: February 14, 2020

Published: February 17, 2020

Copyright $\odot 2020$ by author(s) and Scientific Research Publishing Inc. This work is licensed under the Creative Commons Attribution International License (CC BY 4.0).

http://creativecommons.org/licenses/by/4.0/

\begin{abstract}
The quantification of happiness is gaining attention as one of the new social indicators for measuring the degree of development, as put forward in the Stiglitz Report. Various happiness determinants, including (non-)socio-economic factors, have been proposed. Among these, we explored social capital (SC), which refers to human networks as capital. However, methodology to measure SC inclusively is still under developed. We used the Resource Generator to ask about quasi-resources in human networks in order to measure participants' SC. We administered a survey in the general public in Japan and seven other countries: Denmark, Sweden, Switzerland, Finland, Bhutan, Indonesia, and Singapore. The results showed, first, that a correlation between happiness and SC could be identified in Denmark, Finland, Singapore, and Japan but less so in Sweden, Switzerland, Bhutan, and Indonesia. Second, the countries showed both identical and different characteristics in SC. Third, SC revealed common aspects that affected happiness in each country. Mental support, spending leisure time with others, and one's career were common determinants of SC that contributed to happiness in most of the countries, though some exceptions were found.
\end{abstract}

\section{Keywords}

Happiness, Subjective Well-Being (SWB), Social Capital (SC)

\section{Introduction}

\subsection{Happiness}

Sustainable development is increasingly proposed to solve economic, environ- 
mental, and social problems. Towards a unified definition of this concept, the United Nations (U.N.) has proposed various Sustainable Development Goals. Even so, the idea of sustainable development includes multilateral aspects, and its definition and scope differ by context. The term appears frequently in the discussion of environmental issues, and recent studies have identified three to four components. Tsuda et al. (2006) suggested defining a sustainable society based on the following two kinds of satisfaction: one is the triple bottom line composed of the environment, economics, and society. The other is happiness. Indeed, according to Tsuda et al., happiness is a requisite factor in achieving sustainable development.

Although happiness can be a significant factor in sustainable development and an ultimate goal for human beings, most countries regard economic development as a more important issue. Nonetheless, the means to quantify happiness and various determinants of it have been developed rapidly in the last decades. Stiglitz et al. (2009), which is the bible of this stream, summarized the recent developments in this field and suggested reconsidering adequate social indicators to measure not only economic growth but also degrees of social development such as quality of life, sustainable development, and the environment. Research on happiness originated in psychology and later spreads to economics with the expectation that it would serve as an alternative concept to preference (Frey \& Stutzer, 1999). White (2006) showed country rankings in terms of happiness on the world map. In this ranking, Denmark was the highest, followed by Switzerland, and both Finland and Sweden ranked $5^{\text {th }}$. Many other studies described Denmark and other Nordic nations as happy countries.

The literature on happiness has focused much attention on what makes people happy and unhappy. Studies on this topic have been conducted at the international, national, and even regional levels. For example, Blanchflower and Oswald (2008) found a "U-shaped relationship" between happiness and age. As regards gender and civil status, women are happier than men (Inglehart, 1990), whereas married people are happier than single people (Diener et al., 2000). Psychological factors have been explored as well. For instance, Lachman and Weaver (1998) revealed that people who perceive that they have control over their lives feel happier even if they have less money. Moreover, optimistic people tend to be happier than their pessimistic counterparts (Seidlitz and Diener, 1993). In Denmark, which is one of the happiest countries in the world, Greve (2010) revealed the significant factors that increase Danish happiness. Danish people's happiness depends on age, marital status, and trust, as in other countries. However, gender is not an essential factor in the happiness rating in Denmark, unlike in most other countries.

\subsection{Social Capital}

Stiglitz et al. (2009) described many factors that should be measured to contribute to our understanding of human well-being and to assess the quality of life. 
These include home activities, quality of work, leisure, health, quality of institutions, and social networks. This study explores the characteristics of social capital (SC) as one determinant of happiness. SC is a term in which social networks are considered capital. SC consists of the following three components: trust, norm, and network.

Some existing research has addressed the relationship between happiness and SC. However, SC is still under discussion at the conceptual level (Bjørnskov \& Sønderskov, 2013). Because it has various and sometimes ambiguous definitions, Researchers have used different indicators to quantify it. Moreover, the literature fails to capture a full understanding of SC because most of the indicators used in previous studies rely on proxy variables from other social surveys. Famous methods that have been employed to quantify SC are the name generator and position generator. However, these are not sufficient for use with a large number of respondents. To address such problems, a breakthrough indicator named the Resource Generator (RG) was invented (Van Der Gaag and Snijders, 2005). RG combines the position generator's ease of use with the name generator's measurement of the concrete effect of SC. Other research on SC using RG was conducted in the U.K. (Webber and Huxley, 2007). Similar studies were carried out in Ichihara, Japan (Kurishima et al., 2015) and Tateyama, Japan (Tanaka et al., 2017).

\subsection{This Study}

Previous studies have explored the relationship between happiness and SC (Bjørnskov, 2008; Matsumoto and Maeno, 2010). This research includes two new ideas as follows: measurement and international comparison. As regards measurement, prior research used the name generator or position generator to measure SC or trust data as a proxy of SC. This study uses RG, which is an innovative method because it focuses on the actual effects of human networks. RG helps identify the utility of SC with respect to the effect on happiness, which is valuable for SC management.

Meanwhile, the utility of SC's effect on happiness differs according to the cultural and social background. As such, this work explores the differences between countries. The survey was conducted in seven countries that have different characteristics in terms of economy, welfare, education, environment, and religion. Therefore, not only these target countries but also other countries that have similar characteristics can gain insight from the findings.

\subsection{Country Selection}

For the international comparison, the following seven countries were chosen: Denmark, Sweden, Switzerland, Finland, Bhutan, Indonesia, and Singapore. In addition, survey data from Kurishima et al. (2015) were utilized as the Japanese data for comparison. Some important information about happiness and other social indicators of the seven target countries and Japan are summarized in $\mathrm{Ta}$ ble 1 and Table 2. 
Table 1. Various social indicators (happiness or quality of life).

\begin{tabular}{ccccc}
\hline & $\begin{array}{c}\text { World Happiness } \\
\text { Report }\end{array}$ & $\begin{array}{c}\text { Better } \\
\text { Life Index }\end{array}$ & $\begin{array}{c}\text { Human } \\
\text { Development Index }\end{array}$ & $\begin{array}{c}\text { Satisfaction } \\
\text { with Life Index }\end{array}$ \\
\cline { 2 - 5 } & 2017 & 2017 & 2015 & Adrian G. White \\
\hline Denmark & $7.522(2)$ & OECD & UNDP & $273.5(1)$ \\
Sweden & $7.284(10)$ & $7.5(1)$ & $0.925(5)$ & $256.67(5)$ \\
Finland & $7.469(5)$ & $7.3(7)$ & $0.913(14)$ & $256.67(5)$ \\
Switerland & $7.494(4)$ & $7.5(1)$ & $0.895(23)$ & $273.33(2)$ \\
Bhutan & $5.011(97)$ & $7.5(1)$ & $0.939(2)$ & $253.33(8)$ \\
Indonesia & $5.262(81)$ & - & $0.607(132)$ & $220(61)$ \\
Singapore & $6.572(26)$ & - & $0.689(113)$ & $230(48)$ \\
Japan & $5.920(51)$ & $5.9(30)$ & $0.925(5)$ & $206.67(88)$ \\
\hline
\end{tabular}

https://worldhappiness.report/ed/2017/;

http://www.oecdbetterlifeindex.org/; http://hdr.undp.org/en ;

https://www.unenvironment.org/resources/report/inclusive-wealth-report-2018; https://core.ac.uk/display/102882880.

Table 2. Various social indicators (others).

\begin{tabular}{|c|c|c|c|c|c|c|c|c|c|c|}
\hline & \multirow{2}{*}{$\begin{array}{c}\text { GDP per } \\
\text { capital [US\$] }\end{array}$} & \multicolumn{3}{|c|}{ PISA } & \multirow{2}{*}{ EAPI } & \multirow{2}{*}{$\begin{array}{l}\text { unemployment } \\
\text { rate [\%] }\end{array}$} & \multirow{2}{*}{$\begin{array}{l}\text { GINI } \\
\text { index }\end{array}$} & \multirow{2}{*}{$\begin{array}{l}\text { suicide } \\
\text { rate [\%] }\end{array}$} & \multirow{2}{*}{$\begin{array}{c}\text { Net } \\
\text { immigrants }\end{array}$} & \multirow{2}{*}{$\begin{array}{c}\text { Social } \\
\text { expenditure }\end{array}$} \\
\hline & & science & reading & math & & & & & & \\
\hline & 2016 & 2015 & 2015 & 2015 & 2017 & 2017 & - & 2015 & 2015 & 2013 \\
\hline & World Bank & & OECD & & $\begin{array}{l}\text { World Economic } \\
\text { Forum }\end{array}$ & IMF & CIA & WHO & UN & OECD \\
\hline Denmark & $53,549.7(10)$ & (21) & (18) & $(12)$ & (4) & $5.8(63)$ & $28.8(132)$ & 0.0091 & (33) & (4) \\
\hline Sweden & $51,949.3(12)$ & (28) & (17) & $(24)$ & (3) & $6.6(53)$ & $24.9(145)$ & 0.0127 & (27) & (7) \\
\hline Finland & $43,402.9(18)$ & (5) & (4) & (13) & (12) & $8.7(35)$ & $21.5(150)$ & 0.0142 & (39) & (9) \\
\hline Switerland & $79,890.5(2)$ & (18) & (28) & (8) & (1) & $3(100)$ & $29.5(128)$ & 0.0107 & (20) & (3) \\
\hline Bhutan & $2773.5(163)$ & - & - & - & - & $3.2(98)$ & $38.8(69)$ & 0.0121 & (62) & - \\
\hline Indonesia & $3570.3(151)$ & (62) & (64) & $(63)$ & (50) & $5.4(71)$ & $36.8(81)$ & 0.003 & (196) & - \\
\hline Singapore & $52,962.5(11)$ & (1) & (1) & (1) & (39) & $2.2(106)$ & $45.8(36)$ & 0.0086 & (23) & - \\
\hline Japan & $38,900.6(26)$ & (2) & (8) & (5) & (45) & $2.9(101)$ & $37.9(73)$ & 0.0154 & (22) & (18) \\
\hline
\end{tabular}

Inside of parenthesis: Ranking number. https://data.worldbank.org/indicator/NY.GDP.PCAP.CD;

https://www.cia.gov/library/publications/the-world-factbook/rankorder/2172rank.html.

As Table 1 shows, the four European countries in this study are well known as happy countries. Denmark is ranked first, Sweden tenth, Finland fifth, and Switzerland fourth in the latest World Happiness Report (WHR) (Helliwell et al., 2017). Denmark, Sweden, Finland, and Switzerland rank high in many other surveys as well. The common characteristics of these countries are a high GDP per capita and high taxes, which are used for high-level welfare and environmental provision; see the Energy Architecture Performance Index (EAPI) and social expenditure values in Table 2 . These social backgrounds are considered to affect people's happiness. 
Bhutan is famous for its unique national strategy for maximizing people's happiness, called Gross National Happiness. Although Bhutan hardly appears in major happiness rankings (such as the WHR summarized in Table 1) because of its low development level; it is nonetheless strongly recognized as a happy country by both citizens and foreigners. Bhutan's GDP per capita was ranked $163^{\text {rd }}$ in the world, as Table 2 shows, and accordingly, the living standard is considerably low. However, the government prioritizes its budgets for welfare and education over development. In addition to these economic and social situations, Bhutan is historically a Buddhist country.

Indonesia is a developing country exhibiting rapid economic growth. Consequently, environmental pollution and disparity, which may contribute to negative results (see Table 1), are emerging as serious problems. Although Indonesia has a graduated taxation system, increasing corruption has led to citizens' dissatisfaction. Moreover, the ethnic Chinese population owns a large amount of capital in Indonesia. The country is religiously diverse, with Muslim, Christian, Hindu, and Buddhist citizens, which has led to political conflicts.

Singapore is the richest country in Southeast Asia. The GDP per capita is no less than that in Europe and the U.S., as shown in Table 2. However, the happiness ranking is relatively low compared to other developed countries (see Table 1). Watanabe et al. (2015) reported that Singapore demonstrates inferiority in non-inequality, freedom to make life choices, and generosity as happiness determinants, compared to Finland, which has a high GDP per capita and high happiness score. To maintain competitiveness, taxes are extremely low and Singapore does not provide courteous welfare services. It has several universities that are famous worldwide, and Singaporean basic academic ability is rated highly by the Programme for International Student Assessment (PISA). However, because their competition is severe, some of them are suffering from the disparity explained by the GINI index in Table 2. Singapore accepts a large number of foreign immigrants (but only highly educated people or workers with limited stay), as indicated in Table 2. The largest ethnic population is Chinese, followed by Malay and Indian, in that order.

Likewise, the target countries were selected to be diverse in terms of economy, welfare, education, environment, and religion.

\section{Literature Review}

This section reviews four studies that compared happiness in multiple countries. First, a U.N. report (2017) on a large-scale happiness survey will be introduced. Second, OECD (2011), which introduced various indicators for understanding social progress, is examined. This work quantified both subjective well-being (SWB) and SC. Third, Tachibanaki and Sakoda (2016), which summarized the latest happiness research, is discussed. Tachibanaki is well known in Japan as one of the most famous economists who investigates happiness. Finally, other studies on happiness that compare multiple countries are introduced. 


\subsection{WHR}

U.N. published the WHR, in which survey respondents report their own happiness level on a scale of 0 to 10 (Cantril Ladder). The data are based on the Gallup survey. The scores are explained by the following six factors: GDP per capita, social support, healthy life expectancy, freedom to make life choices, generosity, and perception of corruption. There are 155 target countries. The 2017 ranking is topped by Norway, followed by Denmark, Iceland, Switzerland, Finland, Netherlands, Canada, New Zealand, Australia, and Sweden, in this order. The ranking for the target countries in this study is shown in Table 1 and Table 2. An interesting point of the U.N. report is the large scale of the survey. The results are frequently used for reference in happiness research (Helliwell et al., 2017).

The current work is different from the U.N. survey in two ways. First, survey of this work was conducted on the street, and thus the demographic characteristics of respondents are different from that in the U.N. report. This has both positive and negative implications. This paper shows a higher score of happiness in most of the countries compared with the U.N. report. Second, the factors that explain happiness differ between the U.N. study and current one. As happiness depends on various factors, both studies clarify different angles in happiness researches.

\subsection{How's Life? Measuring Well-Being}

The OECD published "How's life? Measuring well-being". Its data are utilized in the "Better life index", which allows a personalized selection of social indicators; nation-wide rankings are provided on their website. The "How's life?" report suggests the necessity of comprehensive well-being indicator comparable across all over the countries. "Well-being" includes not only SWB but also various social indicators to measure social progress. In this report, well-being is thought to consist of the following three concepts: material life level, life quality, and sustainability. The first two concepts are measured by income, jobs, housing, health, work-life balance, education, social connections, civic engagement and governance, environment, personal security, and SWB. Meanwhile, quantification of sustainability is excluded in the report data because of its development in underway and is excluded in the report data. The report provides detailed information for each category and does not rank countries based on all the indicators.

Although the report tries to grasp well-being comprehensively using not just a single indicator but multiple ones, it still mentions SWB measured by life satisfaction and positive emotion. Life satisfaction is measured by a scale with the Cantril Ladder, which asks respondents to describe 10 as the conceivable best life and to describe 0 as the conceivable worst life as in the WHR. On the other hand, positive emotion is measured by the percentage of people in each country who reported having positive emotions rather than negative ones the day before the survey. In general, people had more positive emotions than negative ones. The Netherlands and most of the Scandinavian countries, namely Denmark, 
Norway, and Sweden, ranked higher than others in both measurements. Finland, Switzerland, Israel, Italy, and Canada ranked higher in the measure of life satisfaction. Meanwhile, Asian countries like China, Indonesia, and Japan ranked higher in positive emotion.

The "How's life?" report also mentioned SC as a well-being determinant that measures support from social networks, frequency of social contact, time for volunteer activities, and trust in others. However, the report noted that there is no established method for measuring SC, and that available and trustworthy data were limited. As such, although they used data from the Gallup World Poll and other social surveys, the report authors regarded this measurement as the next best thing.

There are two differences between the "How's life?" report and this paper. First, the approach used to measure SC is different, as mentioned in the previous section. Second, although this report provides statistical information both about happiness and SC, correlations and rankings are not calculated.

\subsection{Comparative Study of Happiness and Inequality}

Japanese researchers have also undertaken international comparisons of happiness. For example, Tachibanaki \& Sakoda (2016) conducted a survey for happiness comparison among five countries (U.S., U.K., France, Germany, and Japan) focusing on inequality and psychological characteristics as happiness factors. In their survey, the U.S. emerged as the happiest among the five countries, whereas Japan was the lowest. The three European countries were ranked in the middle. There are two main findings in their research. First, they found that neuroticism, according to the "Big Five" theory of psychological factors and personalities, affected happiness negatively in all the countries surveyed. Second, the effect of inequality on happiness differed among the countries. In the U.S., people accepted inequality more positively because they believed everyone had a chance to become rich by working hard. On the other hand, inequality had a negative impact on happiness in Europe and Japan for historical, cultural, and other reasons.

Although it is also an international comparison of happiness, there are two differences between it and this study (Tachibanaki \& Sakoda, 2016). First, the happiness factors studied are different. Tachibanaki \& Sakoda (2016) identified the relationship between happiness and inequality or psychological characteristics, whereas this work focuses on SC. Second, the countries in the comparison are different. They surveyed the U.S. because their interest among the various determinants of happiness was inequality.

\subsection{Other International Comparisons on Happiness and Social Capital}

Not only international organizations but also individual researchers have made international comparisons concerning happiness. Frey, a well-known researcher on happiness who introduced the concept of connecting happiness and eco- 
nomics, revealed the relationship between income and life satisfaction in 51 countries (Frey and Stutzer, 2013). The data were extracted by the World Value Survey in 1997. The life satisfaction shows a concave as a function of GDP per capita relatively low income range (below $\$ 10,000$ ). However, the happiness level becomes more stable after a certain point, and the per capita income has a limited influence on happiness.

Bjørnskov, who lives in one of the happiest countries, Denmark, contributes greatly to this area of knowledge. He found that in 70 countries, the happiness determinants included openness, business climate, post-communism, the number of chambers in parliament, Christian majority, and infant mortality (Bjørnskov et al., 2008a). He found also a relationship between formal institution-such as well-functioning legal system, enforcing property rights, insuring citizens against violence and more-or economic performance and happiness (Bjørnskov et al., 2008b), retrieved from 55 countries.

These existing studies had addressed to measure SC across countries, however, we believe our SC measures provide different results with new insights since SC measures are generally still under development.

In addition to the above, Greve (2010) in Denmark revealed relationship between happiness and social policy in multiple European countries, while Huppert et al. (2009) in Switzerland identified happiness-related policy implications and Blanchflower \& Oswald (2008) in UK explored the "U-shape" patterns of happiness in various countries.

\section{Methodology}

\subsection{Quantitative Survey}

\subsubsection{Measurement of Happiness}

To quantify happiness, two measures are used, objective well-being (OWB) and SWB (Frey and Stutzer, 2002). OWB utilizes physiological methods such as the measurement of brain waves. The merit is that OWB is able to measure happiness accurately without influence by individual memory and cognitive process. However, because this method should define unified criteria of happiness, it cannot necessarily capture individual happiness. Human happiness is complex and depends on culture and society.

SWB asks participants to express their level of happiness directly. They choose one answer from several choices. This method is adopted in the present research. The questionnaire asks respondents, "How happy are you? Please describe your degree of happiness on a scale from $0-10$ ". The merit of this method is that it can grasp the factors that contribute to happiness. A weakness, however, is lack of its robustness. Each answer can change depending on the respondent's feelings, and as such, the data are relatively unstable compared with that of OWB. Nonetheless, although the definition of happiness varies by person, the respondents can describe their happiness based on their own definition in this method. Thus, the approach enables a comprehensive expression of happiness influenced by multiple factors. 


\subsubsection{Measurement of Social Capital}

In this work, SC is measured by RG, as already mentioned. RG is a checklist of 30 items, given in Table 3. Each item describes the person called the "resource", from whom the respondents can ask help in various situations. For example, the first resource is "anyone who knows a lot about delicious shops (restaurants)". The respondents indicate what kind of people can help them for each resource, from the answer choices "Immediate family", "Acquaintance in the neighborhood", "Acquaintance outside the neighborhood", "Organization in the neighborhood", and "Organization outside the neighborhood". If the respondents know anyone from whom they can ask such information, they were regarded as having this resource. The items were created by Japanese researchers and have been utilized in other surveys in Ichihara, Japan (Kurishima et al., 2015). The Japanese data were also contributed to a comparison with the results of this research. Most of the contents were translated from the Japanese questionnaire, with a few questions changed. The strong point of RG is that it can measure the

Table 3. Resource list.

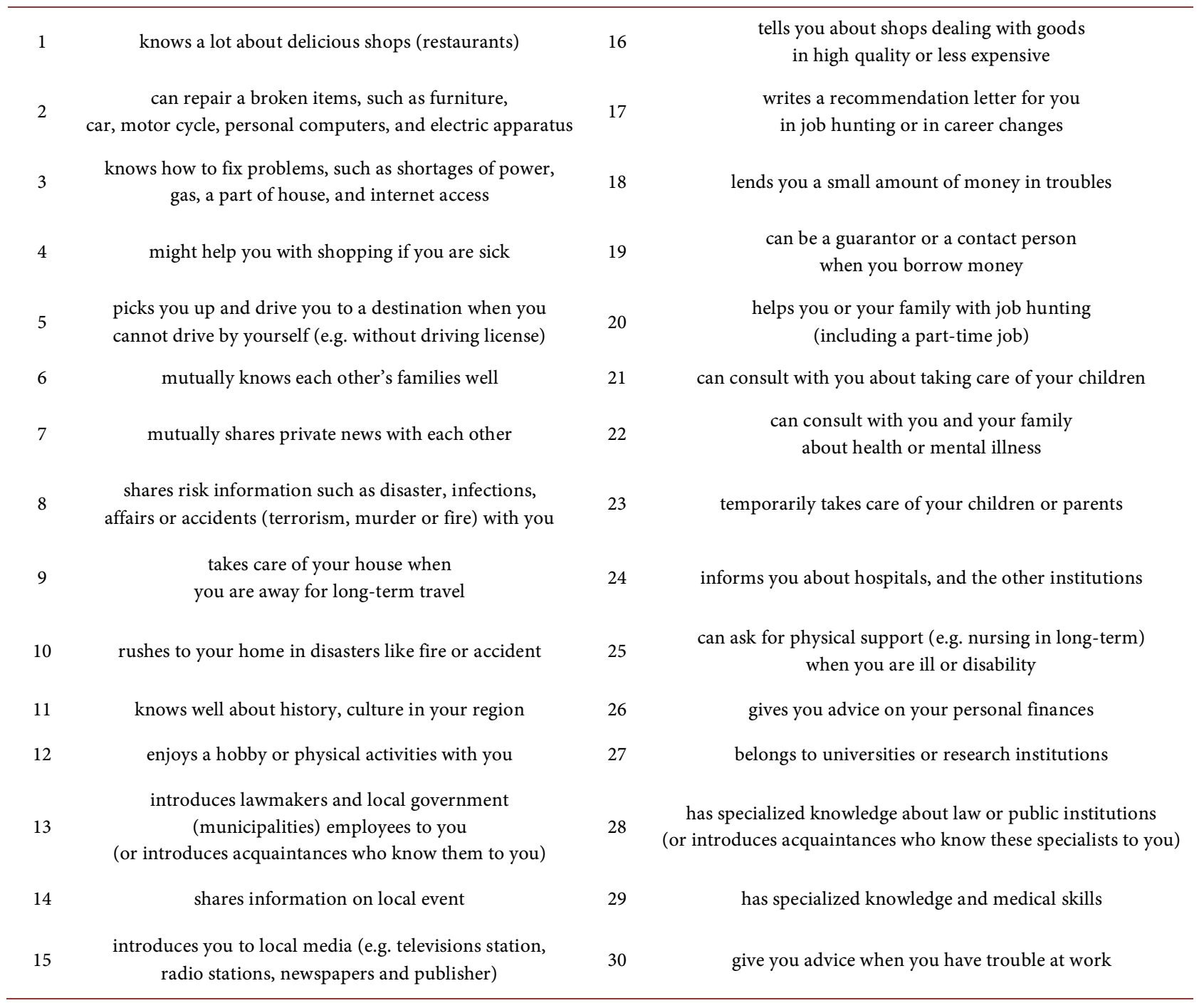


utility of SC. All resources were added because they seemed useful for people in various situations.

In addition to RG, the questionnaire included items related to SC, including one item about the organizations to which the participants belonged and another about their number of acquaintances.

\subsubsection{Survey Administration}

The survey was conducted in the four European and three Asian countries identified above. To collect samples, both paper and online questionnaires were used. Respondents were found at transport stations, libraries, parks, universities, Christmas markets, and food courts for the paper questionnaire, and through Facebook for the online questionnaire. The majority of the respondents were found at train stations to avoid choosing a biased social group. The respondents were asked to answer by paper survey, but those who expressed not having the time to do so were given flyers for the online survey. There were a total of 1,095 respondents (Denmark: 183; Sweden: 137; Finland: 146; Switzerland: 159; Bhutan: 188; Indonesia: 143; and Singapore: 139).

Table 4 shows the number of paper and online questionnaires retrieved. To collect answers efficiently, the survey was conducted in one region in each country except for Bhutan: Arhus in Denmark, Gothenburg in Sweden, Basel in Switzerland, Jyvaskyla in Finland, Paro/Thimphu/Punakha in Bhutan, Bandung in Indonesia, and the whole area of Singapore.

To address the potential respondent bias, the numbers of respondents were adjusted. The respondents were grouped by gender (male and female) and age (below 30, 30 - 39, 40 - 49, 50 - 59, and above 60 years old). Each group included at least 10 respondents, except for that of Sweden. Table 5 shows the number of participants in each gender-age by country, including both the paper and online survey. The respondents were people who lived in each country, including immigrants. However, in the case of Singapore, because the percentage of immigrants and short-term visitors is high, the valid respondents were limited to people who had either lived in Singapore for more than five years or held permanent resident visa status.

\subsection{Qualitative Survey}

In addition to the quantitative paper/online survey, qualitative research was conducted in the form of face-to-face interviews. Although the main analysis is

Table 4. Numbers of respondents.

\begin{tabular}{ccccccccc}
\hline & DK & SE & FI & CH & BT & ID & SG & JP \\
\hline Questionnaire (Paper) & 119 & 125 & 116 & 137 & 188 & 142 & 103 & 432 \\
Questionnaire (Online) & 64 & 12 & 30 & 22 & 0 & 1 & 36 & 0 \\
Interview & 10 & 3 & 10 & 10 & 10 & 10 & 10 & 0 \\
\hline
\end{tabular}

1) DK: Denmark, SE: Sweden, FI: Finland, CH: Switzerland, BT: Bhutan, ID: Indonesia, SG: Singapore, and JP: Japan. 
Table 5. Gender and age balance of respondents. Unit: people (\%).

\begin{tabular}{|c|c|c|c|c|c|c|c|c|}
\hline & \multicolumn{2}{|c|}{ DK } & \multicolumn{2}{|c|}{ SE } & \multicolumn{2}{|c|}{ FI } & \multicolumn{2}{|c|}{$\mathrm{CH}$} \\
\hline & M & $\mathrm{F}$ & M & F & M & $\mathrm{F}$ & M & F \\
\hline-29 & $38(20.8)$ & $38(20.8)$ & $40(29.2)$ & $33(24.1)$ & $13(8.9)$ & $14(9.6)$ & 19 (11.9) & $23(14.5)$ \\
\hline $30-39$ & $13(7.1)$ & $12(6.6)$ & $7(5.1)$ & $2(1.5)$ & $16(11.0)$ & $16(11.0)$ & $15(9.4)$ & $23(14.5)$ \\
\hline $40-49$ & $12(6.6)$ & $13(7.1)$ & $11(8.0)$ & $8(5.8)$ & 17 (11.6) & $14(9.6)$ & $12(7.5)$ & $10(6.3)$ \\
\hline $50-59$ & $16(8.7)$ & $16(8.7)$ & $8(5.8)$ & $7(5.1)$ & $10(6.8)$ & 20 (13.7) & $10(6.3)$ & $20(12.6)$ \\
\hline \multirow[t]{3}{*}{$60-$} & $10(5.5)$ & $10(5.5)$ & $12(8.8)$ & $7(5.1)$ & $12(8.2)$ & $12(8.2)$ & $12(7.5)$ & $11(6.9)$ \\
\hline & \multicolumn{2}{|c|}{ BT } & \multicolumn{2}{|c|}{ ID } & \multicolumn{2}{|c|}{ SG } & \multicolumn{2}{|c|}{ JP } \\
\hline & M & $\mathrm{F}$ & M & $\mathrm{F}$ & M & $\mathrm{F}$ & M & $\mathrm{F}$ \\
\hline-29 & $17(9.0)$ & $24(12.8)$ & $29(20.3)$ & $16(11.2)$ & $15(10.8)$ & $20(14.4)$ & $11(2.5)$ & $16(3.7)$ \\
\hline $30-39$ & $28(14.9)$ & $18(9.6)$ & $11(7.7)$ & $11(7.7)$ & $12(8.6)$ & $13(9.4)$ & $14(3.2)$ & $25(5.8)$ \\
\hline $40-49$ & $26(13.8)$ & $15(8.0)$ & $13(9.1)$ & $12(8.4)$ & $16(11.5)$ & $11(7.9)$ & $15(3.5)$ & $28(6.5)$ \\
\hline $50-59$ & $15(8.0)$ & $13(6.9)$ & $11(7.7)$ & $11(7.7)$ & $10(7.2)$ & 15 (10.8) & $30(6.9)$ & $45(10.4)$ \\
\hline $60-$ & $14(7.4)$ & $12(6.4)$ & $10(7.0)$ & $13(9.1)$ & $16(11.5)$ & $10(7.2)$ & $121(28.0)$ & $124(28.7)$ \\
\hline
\end{tabular}

1) Numbers show exact respondents with percentage in parenthesis; 2) M: male, F: female; 3) The left column indicates ages.

done based on the quantitative data, the results of the qualitative interview are utilized to interpret the results of the quantitative analysis.

The interview consisted of questions on three topics. The first topic, SC, included the following three questions: "When did you felt helped or had a nice feeling from other people recently?", "What is the biggest help you've received from other people in your whole life?", and "How have you helped other people?" The second topic, on happiness, included the following three questions: "Do you think (name of the country) is a happy country in general?", "Why do you think so?", and "What makes you happy?" The final topic was about social problems, consisting of the question, "What kind of serious social problems exist these days, in your opinion?".

\section{Results}

\subsection{Average Happiness and Average SC}

The average of happiness, SC, and the correlation between them in each country were calculated. To quantify happiness, the averages values of all the answers were calculated for each country. For SC, the numbers of resources that each respondent indicated were calculated. The respondents were regarded as having a resource if they could obtain help from at least one category of people. The averages of the total resources were calculated as well. Table 6 shows the results of the calculation, with the standard deviation (in parenthesis), correlation, and $p$-values.

To compare the results, the Japanese dataset was added, as mentioned above. Although the content details were little different from the other seven countries, 
Table 6. Happiness, social capital and correlation.

\begin{tabular}{ccccccccc}
\hline & DK & SE & FI & CH & BT & ID & SG & JP \\
\hline \multirow{2}{*}{ Happiness } & 7.73 & 7.73 & 7.63 & 8.06 & 8.15 & 7.39 & 7.14 & 6.91 \\
& $(1.45)$ & $(1.45)$ & $(1.70)$ & $(1.43)$ & $(2.44)$ & $(1.71)$ & $(1.70)$ & $(2.03)$ \\
Social Capital & 23.3 & 23.2 & 22.7 & 23.4 & 20.7 & 23.7 & 22.7 & 14.8 \\
& $(5.12)$ & $(5.71)$ & $(7.03)$ & $(5.16)$ & $(5.85)$ & $(5.19)$ & $(7.03)$ & $(7.42)$ \\
Correlation & 0.24 & 0.05 & 0.20 & 0.01 & -0.03 & 0.14 & 0.19 & 0.29 \\
$p$-value & 0.001 & 0.617 & 0.018 & 0.947 & 0.679 & 0.102 & 0.030 & 0.000 \\
\hline
\end{tabular}

1) Inside of parenthesis indicates standard deviation.

the data were analyzed in the same way because the total numbers of resources were the same. The Japanese data had the following six original resources: "can ask for English translation", "can ask for help in case of trouble with your PC or electric apparatus", "informs you about hospitals, nursing facility, day care center, and other facilities", "can consult with you about nursing elderly parents or raising children", "talk about nature or environment in your region together", and "can repair broken items such as furniture, bikes, and electric apparatuses".

As Table 6 shows, Bhutan had the highest score, in contrast to the U.N. survey findings (Table 1). The second highest score was garnered by Switzerland, followed by Denmark, Sweden, Finland, Indonesia, Singapore, and Japan. Meanwhile, on SC, Indonesia scored the highest, followed by Switzerland, Denmark, Sweden, Finland, Singapore, Bhutan, and Japan. As regards correlation between happiness and SC, Denmark and Japan had a relatively high correlation with $1 \%$ significance. Finland and Singapore also had correlations with $5 \%$ significance. The other countries did not show a significant correlation between SC and happiness.

In addition to correlation, the relationship between happiness and SC is shown graphically in Figure 1. As the figure shows, SC increases alongside happiness but starts to decline after a certain point, except in Denmark. In Figure 1, because only the Japanese literature refers to other survey data (Kurishima et al., 2015), the curve is far below than the others with no intersection.

\subsection{Cluster Analysis}

Cluster analysis was conducted, and the resources were classified into six groups. Figure 2 shows the results. Based on the findings, a resource list was reordered and each group was given a name (Table 7). The 30 resources were classified into "Diversity of personal connections in academic, legal, and medical areas", "Diversity of personal connections in politics and media", "Technical support", "Other", "Raising children and health of children or parents", and "Economic support and career development". The category "Other" included resources related to the region, help in daily life, support in emergencies, and mental support.

The data from Denmark, Sweden, Finland, Switzerland, Bhutan, Indonesia, 


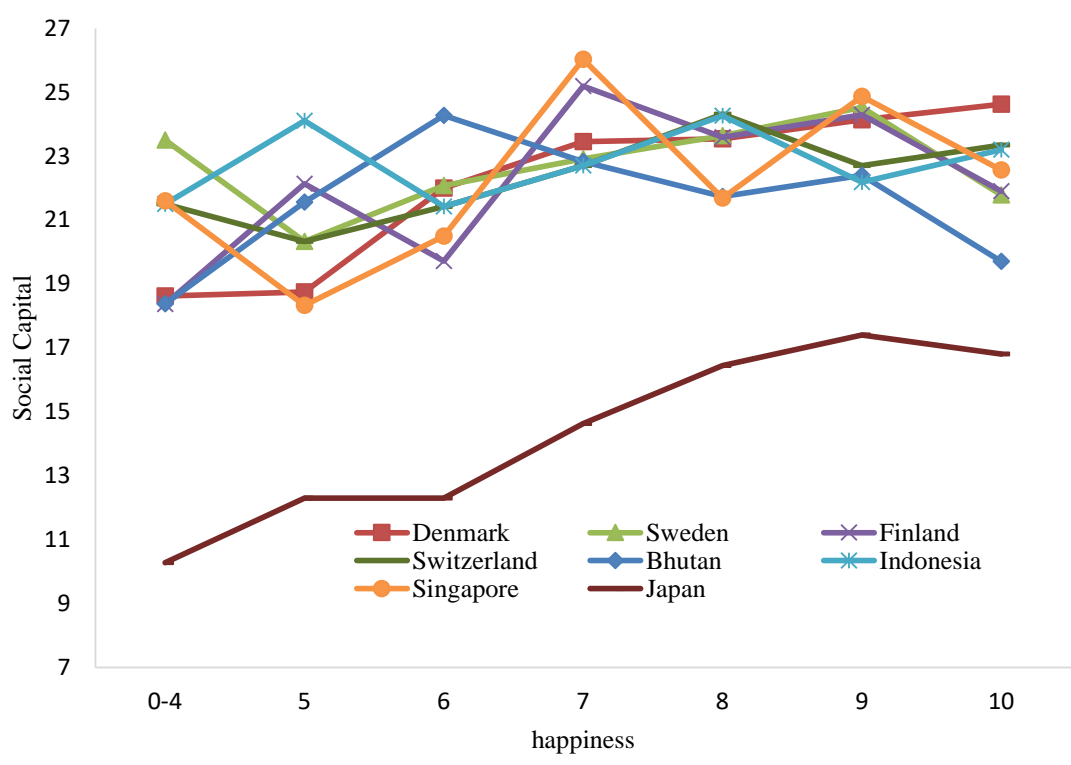

Figure 1. Relationship between happiness and social capital.

Table 7. Resource list after classification based on cluster analysis.

\section{Diversity of personal connection in academic, law and medical area 5}

belongs to universities or research institutions

has specialized knowledge about law or public institutions

(or introduces acquaintances who know these specialists to you)

has specialized knowledge and medical skills

\section{Diversity of personal connection in politics and media}

introduces lawmakers and local government

(municipalities) employees to you

(or introduces acquaintances who know them to you)

introduces you to local media

(e.g. televisions station, radio stations, newspapers and publisher)

Technical support

can repair a broken items, such as furniture, car, motor cycle, personal computers, and electric apparatus

knows how to fix problems, such as shortages of power, gas, a part of house, and internet access

\section{Others}

shares risk information such as disaster, infections, affairs or accidents (terrorism, murder or fire) with you

give you advice when you have trouble at work

knows well about history, culture in your region

shares information on local event

mutually knows each other's families well

mutually shares private news with each other

might help you with shopping if you are sick

picks you up and drive you to a destination when you cannot drive by yourself (e.g. without driving license)

$$
\text { takes care of your house when }
$$$$
\text { you are away for long-term travel }
$$

rushes to your home in disasters like fire or accident

tells you about shops dealing with goods in high quality or less

$$
\text { expensive }
$$

$$
\text { knows a lot about delicious shops (restaurants) }
$$

enjoys a hobby or physical activities with you

\section{Bringing up children and health of children or parents}

can consult with you about taking care of your children

temporarily takes care of your children or parents

gives you advice on your personal finances

can ask for physical support (e.g. nursing in long-term) when you are ill or disability

can consult with you and your family about health or mental illness

informs you about hospitals, and the other institutions

\section{economical support and career development}

lends you a small amount of money in troubles

can be a guarantor or a contact person when you borrow money

writes a recommendation letter for you

in job hunting or in career changes

helps you or your family with job hunting (including a part-time job) 
and Singapore were then clustered excluding Japan with its (containing a bit different questions and) larger sample number enough to hide the others.

Based on the results of cluster analysis, the acquisition rate of each group was calculated. The results are summarized in Figure 3. As a whole, the shape of the graphs for Bhutan and Singapore looks different from those of graph for other countries. The Bhutanese have fewer resources, as shown in "Diversity of personal connections in academy, law, and medical areas" and "Technical support". However, the acquisition rate of "raising children and health of children or parents", "Diversity of personal connections in politics and media", and "Other" were relatively higher than that of the other resource groups. In Singapore, people have fewer "Technical support" resources but more resources related to "Diversity of personal connections in politics and media".

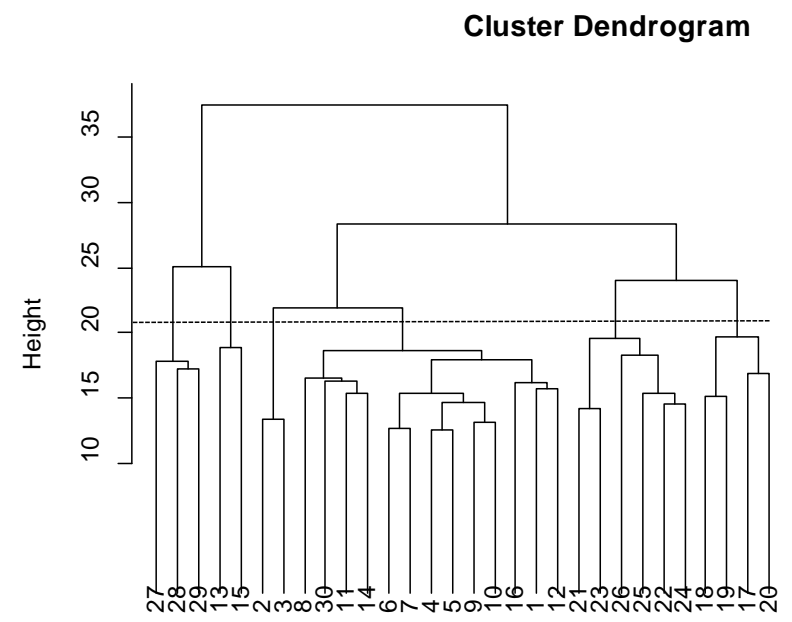

Figure 2. Results of cluster analysis classifying thirty resources.

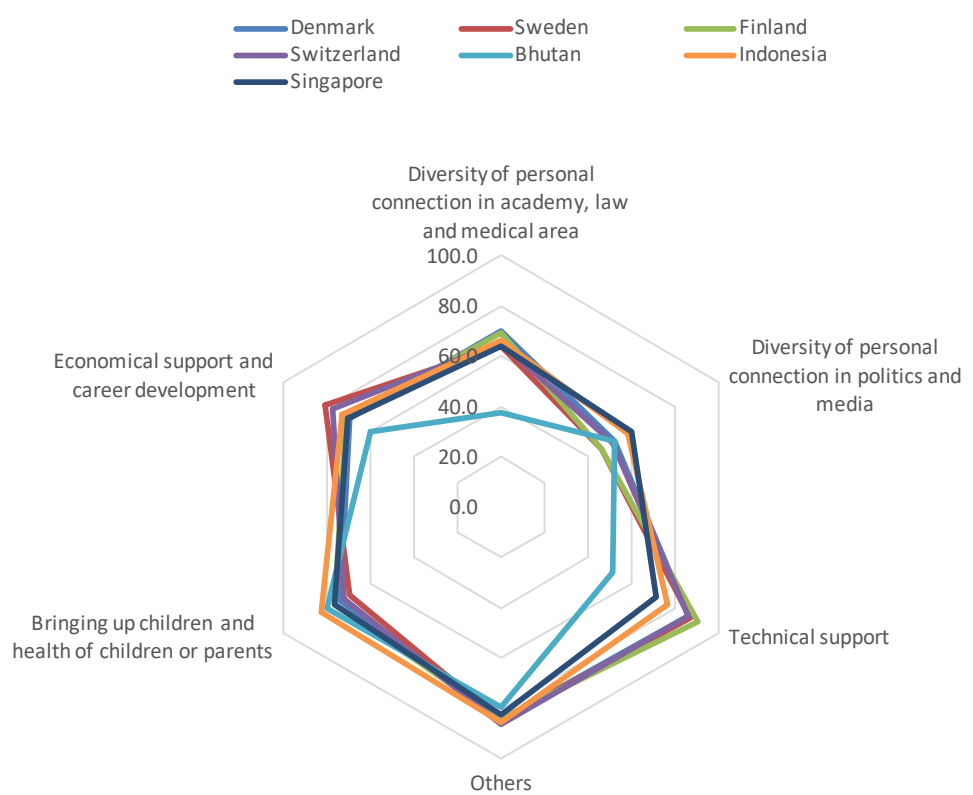

Figure 3. Comparison of acquisition rates of resources [\%]. 


\subsection{Results from the RG}

Table 8 shows the results of the RG measure. Some resources for which there are no Japanese data are indicated as "-". Chi-squared tests were conducted for each resource. The respondents were divided into three groups, namely low, middle, and high, based on the happiness level in each country. As the average happiness scores and distributions differed across the countries, the criteria for grouping were adjusted based on the shape of the graph for happiness and SC (Figure 1). Basically, a value of 0 - 6 indicates a low level; 7 - 8, middle level; and 9 - 10, high level, except for Sweden and Bhutan. In Sweden, SC dips at the point that happiness is 7 , and thus, low is $0-7$, middle is 8 , and high is $9-10$. In Bhutan, the shape of the happiness-SC graph is greatly different from that of other countries. The SC goes up with an increase in happiness, but the peak SC is when happiness is 6, after which SC goes down with the increase in happiness. Thus, for Bhutan, low is $0-5$, middle is $6-7$, and high is $8-10$.

Table 9 shows the supplier of each resource. People generally obtain resources from their family. Notably, the percentage of those who obtain resources from their family is relatively smaller in Japan.

\subsection{Other Happiness Factors}

The correlations between happiness and some factors were calculated as well, including demographic factors, organization membership, and number of surrounding people. Table 10 presents the correlation between happiness and demographic factors. The correlations between happiness and gender, age, having a partner, marital status, income, level of education, and religion were explored. However, because the Japanese dataset did not have demographic information except for gender, only the correlation between happiness and gender was calculated. For gender, female was replaced by " 1 " as a dummy and male with " 0 ". Although females show more happiness in most existing research, our analysis showed that this only applies to Japan.

For partnership, people who were married or were in a relationship were coded " 1 " and singles, " 0 ". On the other hand, for the analysis by marriage, only people who were married received " 1 " and those who were single, whether in a partnership or not, received "0". Being married was relatively well correlated with happiness compared with having a partner.

For income, the answer options were adjusted to each country. To calculate correlation between income and happiness, answers which showed middle to high income in each country were coded "1", and lower income, "0". Income was well correlated with happiness, especially in European countries, except for Denmark.

For education, the first line means whether the respondent graduated from primary school or not. Because primary education is mandatory in most of the countries, the question was asked only in Bhutan. (Bhutan currently provides primary education for free, but some members of the older generations did not 
Table 8. Acquisition rates or resources in each happiness level (unit: \%).

\begin{tabular}{|c|c|c|c|c|c|c|c|c|c|c|c|c|c|c|c|c|}
\hline & & Denma & & & & Swed & len & & & Finlar & & & & Switzerl & land & \\
\hline & low & middle & high & & low & middle & high & & low & middle & high & & low & middle & high & \\
\hline 1 & 69.2 & 80.8 & 88.2 & & 86.3 & 77.5 & 94.1 & & 69.0 & 85.5 & 80.9 & & 77.8 & 90.9 & 88.9 & \\
\hline 2 & 92.3 & 81.8 & 88.2 & & 90.0 & 85.0 & 88.2 & & 93.1 & 95.7 & 87.2 & & 77.8 & 87.0 & 85.7 & \\
\hline 3 & 92.3 & 87.9 & 84.3 & & 84.0 & 92.5 & 85.3 & & 82.8 & 92.8 & 85.1 & & 83.3 & 85.7 & 90.5 & \\
\hline 4 & 80.8 & 92.9 & 88.2 & & 89.8 & 95.0 & 100.0 & & 82.8 & 92.8 & 93.6 & & 94.4 & 89.6 & 90.5 & \\
\hline 5 & 84.6 & 88.9 & 90.2 & & 90.0 & 97.5 & 88.2 & & 82.8 & 91.3 & 89.4 & & 83.3 & 89.6 & 87.3 & \\
\hline 6 & 76.9 & 81.8 & 90.2 & & 87.8 & 95.0 & 82.4 & & 65.5 & 87.0 & 87.2 & $* *$ & $\underline{55.6}$ & 93.5 & 93.5 & $* * *$ \\
\hline 7 & 69.2 & 92.9 & 90.2 & $* * *$ & 91.8 & 94.9 & 88.2 & & $\underline{72.4}$ & 91.3 & 91.5 & $* *$ & 83.3 & 96.1 & 95.2 & \\
\hline 8 & 65.4 & 79.8 & 80.4 & & 85.7 & 74.4 & 73.5 & & 62.1 & 85.5 & 74.5 & $* *$ & 94.4 & 75.3 & 74.2 & \\
\hline 9 & 80.8 & 80.8 & 90.2 & & 83.7 & 89.7 & 94.1 & & 79.3 & 82.6 & 87.2 & & 88.9 & 88.3 & 92.1 & \\
\hline 10 & 80.8 & 84.8 & 92.2 & & 85.7 & 92.3 & 88.2 & & 69.0 & 87.0 & 80.9 & & 88.9 & 92.2 & 87.3 & \\
\hline 11 & 80.8 & 84.8 & 88.2 & & 85.7 & 74.4 & 73.5 & & 75.9 & 85.5 & 85.1 & & 72.2 & 88.3 & 80.6 & \\
\hline 12 & $\underline{76.9}$ & 92.9 & 98.0 & $* * *$ & 87.8 & 84.6 & 79.4 & & 72.4 & 84.1 & 91.5 & * & 72.2 & 84.4 & 88.7 & \\
\hline 13 & $\underline{23.1}$ & 40.4 & 56.9 & $* *$ & 26.7 & 41.0 & 36.4 & & 31.0 & 48.5 & 46.8 & & 44.4 & 49.4 & 47.5 & \\
\hline 14 & 80.8 & 89.9 & 84.3 & & 80.0 & 87.2 & 93.9 & & 79.3 & 85.3 & 93.6 & & 94.4 & 87.0 & $\underline{75.4}$ & * \\
\hline 15 & 46.2 & 62.6 & 68.6 & & 56.8 & 56.4 & 60.6 & & 34.5 & 50.0 & 51.1 & & 61.1 & 51.9 & 57.4 & \\
\hline 16 & $\underline{57.7}$ & 83.8 & 84.3 & $* * *$ & 71.1 & 69.2 & 84.8 & & 62.1 & 77.9 & 83.0 & & 88.9 & 79.2 & 63.9 & $* *$ \\
\hline 17 & $\underline{42.3}$ & 69.7 & 64.7 & $* *$ & 79.5 & 84.6 & 78.8 & & 65.5 & 72.1 & 70.2 & & 66.7 & 75.3 & 64.5 & \\
\hline 18 & 76.9 & 81.8 & 90.2 & & 84.1 & 89.7 & 90.9 & & 75.9 & 89.7 & 87.2 & & 83.3 & 88.3 & $\underline{72.6}$ & * \\
\hline 19 & 65.4 & 68.7 & 72.5 & & 77.3 & 82.1 & 78.8 & & 55.2 & 70.6 & 63.8 & & 88.9 & 85.7 & 80.6 & \\
\hline 20 & 61.5 & 70.7 & 66.7 & & 79.5 & 74.4 & 75.8 & & 48.3 & 66.2 & 68.1 & & 66.7 & 79.2 & 75.4 & \\
\hline 21 & 65.4 & 62.6 & 58.8 & & 52.3 & 71.8 & 63.6 & & $\underline{55.2}$ & 75.0 & 80.9 & $* *$ & 66.7 & 61.0 & 57.4 & \\
\hline 22 & 80.8 & 88.9 & 82.4 & & $\underline{68.2}$ & 87.2 & 81.8 & * & 72.4 & 88.2 & 85.1 & & 88.9 & 85.7 & 86.9 & \\
\hline 23 & 53.8 & 71.7 & 72.5 & & 65.9 & 74.4 & 60.6 & & 65.5 & 80.9 & 85.1 & & 55.6 & 72.7 & 62.9 & \\
\hline 24 & 69.2 & 74.7 & 78.4 & & 65.9 & 71.8 & 66.7 & & 69.0 & 76.5 & 83.0 & & 72.2 & 79.2 & 73.8 & \\
\hline 25 & 76.9 & 76.8 & 84.3 & & 68.2 & 69.2 & 63.6 & & 69.0 & 85.3 & 83.0 & & 94.4 & 76.6 & 71.0 & \\
\hline 26 & 69.2 & 72.7 & 80.4 & & 68.2 & 71.8 & 75.8 & & $\underline{48.3}$ & 73.5 & 70.2 & $* *$ & 61.1 & 67.5 & 66.1 & \\
\hline 27 & $\underline{61.5}$ & 82.8 & 74.5 & * & 65.9 & 71.8 & 63.6 & & 79.3 & 82.4 & 72.3 & & 55.6 & 58.4 & 59.0 & \\
\hline 28 & 46.2 & 66.7 & 60.8 & & 50.0 & 51.3 & 63.6 & & 37.9 & 64.7 & 59.6 & $* *$ & 72.2 & 67.5 & 64.5 & \\
\hline 29 & 61.5 & 73.7 & 70.6 & & 65.9 & 66.7 & 78.8 & & 62.1 & 75.0 & 72.3 & & 61.1 & 74.0 & 72.1 & \\
\hline 30 & 57.7 & 82.8 & 94.1 & $* * *$ & 88.6 & 89.7 & 87.9 & & 75.9 & 88.2 & 89.4 & & 83.3 & 89.6 & 83.9 & \\
\hline
\end{tabular}




\begin{tabular}{|c|c|c|c|c|c|c|c|c|c|c|c|c|c|c|c|c|}
\hline & \multicolumn{4}{|c|}{ Bhutan } & \multicolumn{4}{|c|}{ Indonesia } & \multicolumn{4}{|c|}{ Singapore } & \multicolumn{4}{|c|}{ Japan } \\
\hline & low & middle & high & & low & middle & high & & low & middle & high & & low & middle & high & \\
\hline 1 & 71.0 & 91.3 & 73.3 & & 82.9 & 89.2 & 93.3 & & 74.4 & 87.7 & 90.0 & & $\underline{55.2}$ & 36.1 & 72.6 & $* * * *$ \\
\hline 2 & 41.9 & 65.2 & 50.4 & & 71.4 & 70.3 & 76.7 & & 62.8 & 69.2 & 73.3 & & - & - & - & \\
\hline 3 & 54.8 & 73.9 & 47.3 & $\star$ & 80.0 & 82.4 & 80.0 & & 67.4 & 73.8 & 83.3 & & - & - & - & \\
\hline 4 & $\underline{74.2}$ & 91.7 & 89.3 & * & 85.7 & 89.2 & 93.3 & & $\underline{72.1}$ & 89.2 & 93.3 & $* *$ & $\underline{65.6}$ & 28.3 & 80.2 & $* * *$ \\
\hline 5 & 64.5 & 82.6 & 71.0 & & 82.9 & 93.2 & 93.3 & & 79.1 & 89.2 & 73.3 & & $\underline{65.8}$ & 27.5 & 83.3 & $* * *$ \\
\hline 6 & 76.7 & 87.0 & 80.9 & & 85.7 & 94.6 & 96.7 & & $\underline{69.8}$ & 6.2 & 90.0 & $* *$ & $\underline{75.2}$ & 21.4 & 85.6 & * \\
\hline 7 & $\underline{56.7}$ & 91.3 & 73.3 & $* *$ & 88.6 & 95.9 & 90.0 & & $\underline{65.1}$ & 86.2 & 86.7 & $* *$ & $\underline{66.2}$ & 27.8 & 81.3 & $* * *$ \\
\hline 8 & $\underline{66.7}$ & 82.6 & 86.3 & $* *$ & 68.6 & 83.8 & 83.3 & & 81.4 & 87.7 & 83.3 & & $\underline{53.9}$ & 37.4 & 70.5 & $; * * *$ \\
\hline 9 & 73.3 & 87.0 & 87.8 & & 85.7 & 86.5 & 83.3 & & 76.7 & 81.5 & 86.7 & & 58.6 & 36.4 & 65.9 & \\
\hline 10 & $\underline{66.7}$ & 83.3 & 84.7 & * & 91.4 & 91.9 & 96.7 & & 72.1 & 83.1 & 83.3 & & $\underline{72.9}$ & 22.6 & 85.2 & $* *$ \\
\hline 11 & 83.3 & 95.7 & 83.2 & & 71.4 & 67.6 & 93.3 & $* *$ & 65.1 & 70.8 & 83.3 & & 26.3 & 72.7 & 25.3 & \\
\hline 12 & 70.0 & 87.0 & 63.4 & * & 77.1 & 85.1 & 96.7 & * & $\underline{72.1}$ & 93.8 & 86.7 & $* * *$ & $\underline{52.6}$ & 38.0 & 70.0 & $* * *$ \\
\hline 13 & 66.7 & 73.9 & $\underline{49.6}$ & $* *$ & 60.0 & 63.5 & 73.3 & & 44.2 & 55.4 & 66.7 & & 17.2 & 76.7 & 22.9 & \\
\hline 14 & 66.7 & 78.3 & 80.2 & & 60.0 & 75.3 & 80.0 & & 79.1 & 92.3 & 86.7 & & 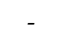 & - & - & \\
\hline 15 & 33.3 & 43.5 & 54.2 & * & 57.1 & 45.2 & 66.7 & & 58.1 & 67.7 & 76.7 & & 7.8 & $\underline{95.9}$ & 3.6 & $* *$ \\
\hline 16 & 63.3 & 82.6 & 84.7 & $* *$ & 88.6 & 91.8 & 96.7 & & 81.4 & 86.2 & 83.3 & & $\underline{42.2}$ & 46.4 & 60.9 & $* * *$ \\
\hline 17 & 53.3 & 56.5 & 46.6 & & $\underline{48.6}$ & 64.4 & 86.7 & $* * *$ & $\underline{58.1}$ & 73.8 & 86.7 & $* *$ & 13.9 & 82.3 & 16.9 & * \\
\hline 18 & 80.0 & 87.0 & 71.0 & & $\underline{74.3}$ & 91.8 & 90.0 & $* *$ & 69.8 & 81.5 & 76.7 & & $\underline{46.1}$ & 45.1 & 59.9 & $* * *$ \\
\hline 19 & 60.0 & 73.9 & 57.3 & & 51.4 & 68.5 & 70.0 & & $\underline{48.8}$ & 73.8 & 66.7 & $* *$ & $\underline{43.5}$ & 47.8 & 57.2 & $* *$ \\
\hline 20 & 50.0 & 65.2 & 56.5 & & 80.0 & 69.9 & 90.0 & * & 65.1 & 72.3 & 73.3 & & 15.3 & 81.4 & 17.5 & * \\
\hline 21 & 80.0 & 87.5 & 80.9 & & 65.7 & 69.9 & 80.0 & & 67.4 & 73.8 & 80.0 & & - & - & - & \\
\hline 22 & 83.3 & 91.7 & 87.8 & & 85.7 & 76.7 & 90.0 & & 74.4 & 84.6 & 90.0 & & $\underline{71.3}$ & 23.9 & 85.1 & $* *$ \\
\hline 23 & 66.7 & 87.5 & 80.2 & & 85.7 & 95.9 & 93.3 & & $\underline{62.8}$ & 81.5 & 76.7 & * & $\underline{44.4}$ & 47.5 & 56.6 & $; * * *$ \\
\hline 24 & 83.3 & 87.5 & 82.4 & & $\underline{74.3}$ & 90.4 & 90.0 & * & $\underline{62.8}$ & 84.6 & 86.7 & $* *$ & - & - & - & \\
\hline 25 & 70.0 & 83.3 & 80.2 & & 80.0 & 90.4 & 90.0 & & $\underline{53.5}$ & 81.5 & 90.0 & * & $\underline{46.4}$ & 43.6 & 62.7 & $* * *$ \\
\hline 26 & 70.0 & 75.0 & 72.5 & & 68.6 & 83.6 & 73.3 & & 69.8 & 84.6 & 70.0 & & $\underline{24.8}$ & 67.3 & 33.5 & $* * * *$ \\
\hline 27 & 40.0 & 56.5 & $\underline{24.4}$ & $* * *$ & 54.3 & 72.6 & 63.3 & & 51.2 & 69.2 & 70.0 & & 9.3 & $\underline{93.2}$ & 6.0 & $* *$ \\
\hline 28 & 46.7 & 60.9 & 38.2 & & 60.0 & 52.1 & 70.0 & & 51.2 & 69.2 & 66.7 & & 18.3 & 75.3 & 24.4 & \\
\hline 29 & 46.7 & 60.9 & $\underline{35.1}$ & $* *$ & 68.6 & 74.0 & 83.3 & & $\underline{44.2}$ & 69.2 & 83.3 & $* * *$ & $\underline{22.5}$ & 69.2 & 31.1 & ${ }^{* *}$ \\
\hline 30 & 83.3 & 87.5 & 87.8 & & 68.6 & 69.9 & 83.3 & & $\underline{72.1}$ & 89.2 & 90.0 & $* *$ & - & - & - & \\
\hline
\end{tabular}

1) 1 to 30 corresponds to resource list in Table 2;2) Results of chi-square analysis depending on happiness level in each country: ${ }^{* *}$ significant with $1 \%,{ }^{* *}$ significant with $5 \%$, and ${ }^{*}$ significant with $10 \%$; 3 ) Bold letters with underline low with $5 \%$ significance, Bold letters high with $5 \%$ significance. 
Table 9. Acquisition rates of resources from each supplier.

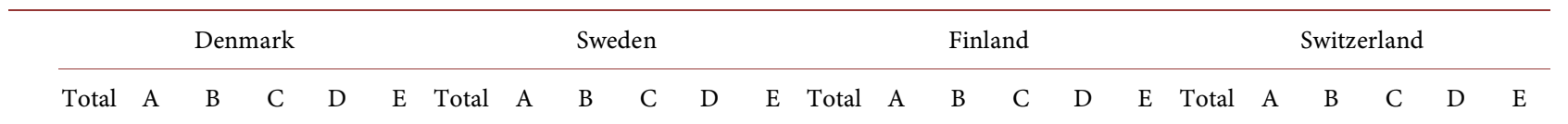

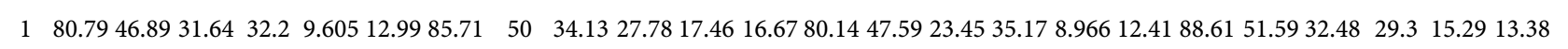

$2 \quad 85.3159 .7829 .0525 .14 \quad 9.50 \quad 6.15 \quad 88 \quad 59.6822 .5825 .81 \quad 12.1 \quad 9.67792 .4762 .7628 .2830 .3410 .3413 .7985 .4458 .3332 .0525 .6413 .4612 .18$

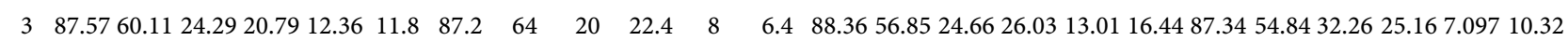

$4 \quad 89.83 \quad 76.4 \quad 41.5719 .662 .8095 .05694 .3582 .1122 .7615 .458 .943 \quad 3.25291 .1 \quad 80.5631 .2518 .06 \quad 6.257 .63990 .5173 .2538 .8519 .758 .9174 .459$

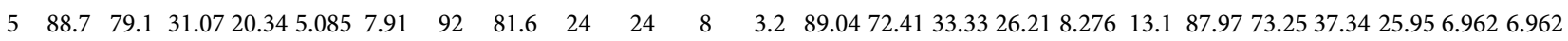

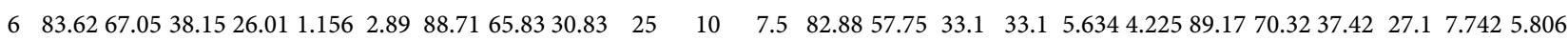

$7 \quad 88.773 .5645 .433 .914 .5984 .59891 .8775 .2130 .5826 .4510 .743 .30687 .6770 .1431 .9439 .58 \quad 6.25 \quad 6.2594 .2776 .9240 .3830 .139 .61510 .26$

$8 \quad 77.9762 .2934 .2928 .5710 .8613 .7178 .8658 .5440 .6529 .2717 .0721 .1477 .461 .8731 .6535 .2515 .1123 .0277 .0767 .5329 .2228 .5713 .6417 .53$

$9 \quad 83.6254 .849 .4417 .422 .8091 .68588 .6269 .1139 .0215 .455 .6914 .06583 .5659 .0345 .8315 .973 .4722 .77889 .8760 .7651 .2715 .197 .5956 .329$ $10 \quad 86.4462 .8655 .4320 .57 \quad 7.4296 .28688 .6265 .8550 .41 \quad 18.7 \quad 8.13 \quad 4.87881 .5154 .5548 .2523 .084 .895 \quad 9.79 \quad 89.8766 .4542 .5819 .3512 .2614 .19$ $1184.7560 .4541 .8127 .8411 .3 \quad 14.1278 .8655 .7429 .5129 .7513 .1113 .1183 .5654 .8634 .7236 .1111 .1112 .583 .4449 .3629 .4932 .6912 .8215 .38$ 1291.5356 .546 .3339 .5512 .9911 .384 .5555 .3736 .3633 .8814 .886 .61284 .2553 .5234 .5142 .969 .85913 .3884 .7149 .6827 .3939 .4910 .1915 .92 $13 \quad 42.3718 .3916 .0910 .929 .19513 .7934 .7521 .3712 .8210 .264 .2747 .69244 .8320 .839 .72211 .116 .94415 .9748 .0825 .1614 .1913 .5510 .32 \quad 12.9$ $14 \quad 86.44 \quad 49.754 .4433 .7318 .3416 .5786 .4454 .2438 .1441 .7923 .81 \quad 19.05 \quad 86.949 .6641 .38 \quad 33.124 .8323 .4583 .3343 .7943 .7937 .2516 .99 \quad 20.92$ $15 \quad 61.58 \quad 35.0927 .4924 .1212 .2811 .758 .1243 .3622 .1222 .129 .735 \quad 7.08 \quad 47.5924 .6516 .2 \quad 20.4211 .9715 .4955 .13 \quad 31.7620 .1322 .158 .72512 .08$

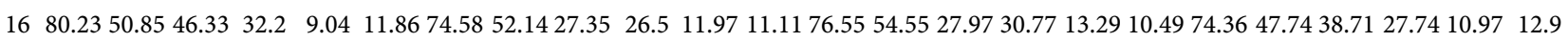
$17 \quad 64.4117 .4414 .53 \quad 30.2312 .7926 .74 \quad 81.2 \quad 26.7224 .14 \quad 30.1727 .5925 .8670 .3413 .3810 .5626 .7626 .0629 .5870 .0628 .3917 .42 \quad 20 \quad 11.61 \quad 16.77$ $18 \quad 83.6278 .2918 .2910 .861 .1435 .14388 .0384 .4815 .5217 .246 .0346 .89786 .2178 .4714 .5814 .584 .8616 .25 \quad 81.53 \quad 76.6220 .7815 .794 .5454 .545$ $19 \quad 69.4962 .5 \quad 10.8 \quad 7.3861 .1364 .54579 .4975 .866 .0348 .6211 .724 \quad 0.86265 .5262 .248 .3922 .7971 .3994 .19684 .0875 .64 \quad 14.1 \quad 10.267 .0515 .769$ 2068.3642 .5329 .8927 .597 .47118 .3976 .9255 .5630 .7723 .9311 .9711 .9762 .7636 .3619 .5823 .0811 .1919 .5876 .2849 .6726 .825 .4913 .0716 .34 $21 \quad 61.5856 .2925 .7519 .168 .3837 .78462 .3958 .41 \quad 17.7 \quad 12.395 .31 \quad 2.655 \quad 73.1 \quad 59.0327 .0820 .836 .94413 .8960 .2654 .9725 .1715 .2311 .26 \quad 5.96$ $2285.3164 .5725 .1424 .5713 .7117 .1478 .6361 .7423 .4821 .74 \quad 11.3 \quad 6.08784 .1454 .1719 .5823 .6113 .8930 .5686 .5466 .0128 .5719 .4813 .6417 .53$ 2368.9361 .5421 .311 .834 .14211 .2467 .5259 .8219 .6413 .393 .5712 .67979 .3159 .7224 .3116 .679 .02816 .6766 .8857 .6223 .8413 .255 .2989 .934 2474.5850 .8626 .4421 .1413 .7120 .5768 .3854 .8723 .8923 .0115 .0416 .8177 .2447 .1825 .3523 .2416 .223 .2476 .2856 .3834 .2320 .1314 .7719 .46 $2578.5363 .0117 .9213 .879 .24916 .7667 .5257 .5213 .2713 .277 .965 \quad 7.08 \quad 81.3863 .6416 .089 .0919 .09118 .1876 .4361 .4420 .9213 .7313 .0716 .34$ $26 \quad 74.5856 .2511 .9313 .079 .09119 .8971 .7953 .9113 .0413 .917 .82613 .0467 .5946 .538 .33310 .4210 .4224 .3166 .2445 .8110 .978 .3877 .74216 .13$ $27 \quad 77.4 \quad 34.4833 .3339 .0815 .5221 .2667 .5232 .1723 .4827 .8313 .9112 .1777 .9334 .5127 .4637 .3222 .5424 .6558 .3326 .4518 .7122 .588 .38712 .26$

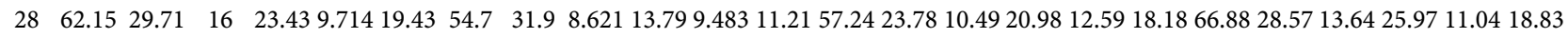
$29 \quad 71.1935 .4322 .2925 .14 \quad 12 \quad 17.7170 .0935 .6514 .7819 .138 .69613 .0471 .7234 .0417 .0224 .828 .51122 .771 .7938 .7119 .3520 .658 .38715 .48$

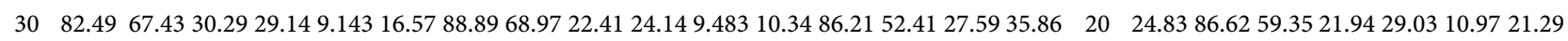
Ave. 77.454 .4730 .5623 .658 .88512 .5277 .4857 .0624 .621 .9110 .799 .51577 .2851 .5725 .0924 .9111 .115 .9277 .9154 .2128 .1322 .6310 .4512 .94 


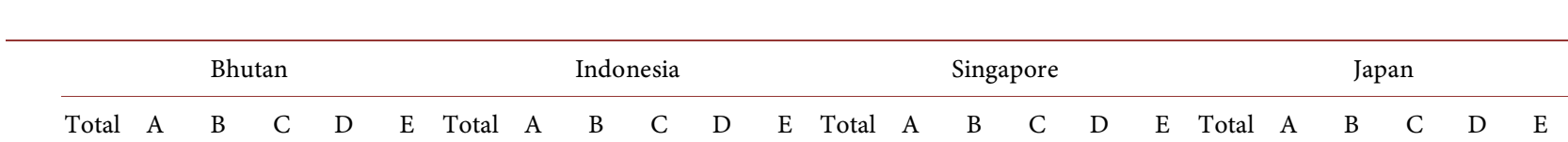

$1 \quad 75.2733 .8830 .058 .19720 .2215 .8588 .4953 .6830 .1523 .539 .55919 .8584 .1749 .2620 .5926 .4717 .6516 .9167 .9845 .2970 .65 \quad 52.92 .8993 .623$

$2 \quad 50.5420 .7715 .38 .19714 .216 .01171 .9433 .8226 .4720 .598 .82415 .4468 .3543 .4817 .3921 .017 .9718 .696 \quad-$

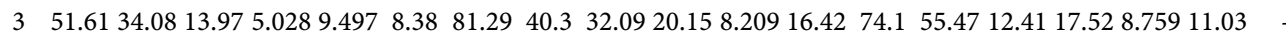

$4 \quad 86.6372 .97 \quad 20 \quad 6.48625 .41 \quad 11.8989 .2171 .74 \quad 18.12 \quad 9.42 \quad 6.5227 .24684 .8974 .8212 .95 \quad 17.276 .475 \quad 1.43975 .3772 .8843 .7924 .181 .307 \quad 0.654$

$5 \quad 70.9751 .1116 .676 .11118 .8911 .6790 .6572 .99 \quad 21.9 \quad 16.066 .56910 .22 \quad 82.7365 .4714 .3916 .556 .4759 .35376 .4172 .3549 .8430 .231 .6081 .286$

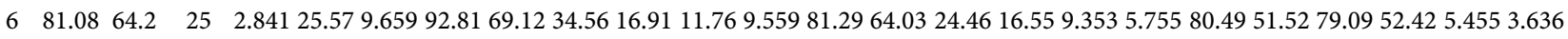

$7 \quad 72.4361 .7612 .356 .47124 .12 \quad 10 \quad 92.8171 .43 \quad 36.0922 .5616 .5415 .0479 .8660 .43 \quad 18.7125 .1810 .073 .59776 .3555 .4864 .1965 .483 .5483 .226$

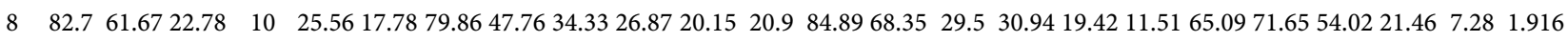

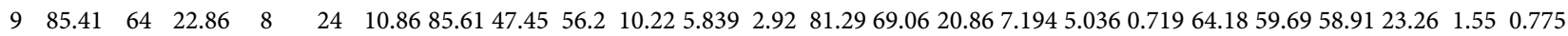

$10 \quad 81.7263 .9533 .7213 .3730 .2316 .8692 .8158 .3956 .216 .7915 .339 .48979 .8669 .5724 .648 .6965 .072 \quad 2.89979 .7153 .9972 .0950 .9210 .432 .147$

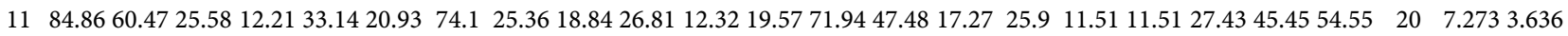

$12 \quad 67.0348 .8618 .757 .95524 .43 \quad 10.8 \quad 85.6140 .7431 .1121 .48 \quad 14.8125 .1985 .6163 .1627 .82 \quad 30.8313 .539 .02364 .1546 .3958 .1744 .114 .9435 .323$

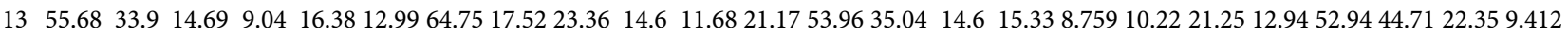

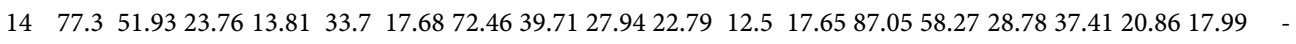

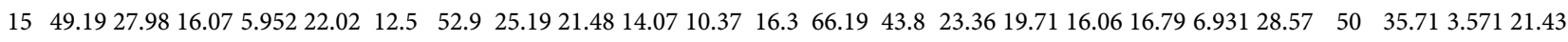
$16 \quad 80.5451 .124 .1810 .9926 .9219 .2392 .0359 .1237 .9624 .0910 .2218 .9884 .1764 .4932 .6132 .6121 .0116 .6753 .9241 .8266 .3629 .554 .5451 .364$ $17 \quad 49.1929 .2112 .367 .86514 .617 .86565 .2226 .87 \quad 20.920 .1514 .93 \quad 19.4 \quad 71.9425 .5516 .0624 .82 \quad 18.2520 .44 \quad 17.5 \quad 41.43 \quad 28.5755 .717 .143 \quad 11.43$ $18 \quad 74.0560 .7718 .33 \quad 6.63 \quad 20.44 \quad 10.5 \quad 86.96 \quad 63.5 \quad 24.82 \quad 16.795 .83911 .68 \quad 76.9869 .78 \quad 16.55 \quad 20.865 .755 \quad 4.31757 .7170 .26 \quad 31.9 \quad 37.07 \quad 0.862 \quad 1.293$ $19 \quad 59.4646 .5913 .144 .54516 .483 .97764 .4949 .63 \quad 15.567 .4072 .2225 .92664 .7558 .399 .4899 .489 \quad 2.92 \quad 3.65 \quad 51.6 \quad 61.7230 .6249 .28 \quad 0 \quad 1.435$ $20 \quad 56.2242 .6914 .627 .01818 .134 .67876 .8147 .4128 .1514 .0714 .0719 .2670 .5 \quad 45.2623 .3623 .3612 .4113 .1418 .5543 .2448 .6539 .192 .7038 .108$ $21 \quad 81.7270 .5621 .113 .33317 .22 \quad 10 \quad 71.0160 .8723 .9113 .046 .5227 .24673 .3865 .41 \quad 19.55 \quad 18.8 \quad 8.2715 .263 \quad-$

$22 \quad 87.1 \quad 69.4426 .118 .88925 .569 .44481 .88 \quad 52.9 \quad 26.81 \quad 16.67 \quad 7.24611 .5982 .7373 .9120 .44 \quad 21.9 \quad 9.48910 .95 \quad 78.4 \quad 66.2555 .4256 .352 .7862 .786$ $2378.4968 .9713 .793 .44825 .298 .62192 .7572 .4634 .0613 .778 .69610 .8774 .8270 .914 .9311 .283 .7312 .23954 .0964 .2241 .2844 .04 \quad 3.67 \quad 1.376$

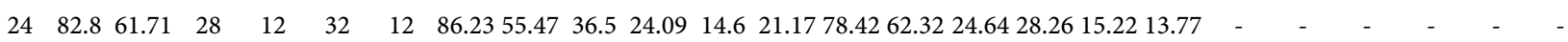

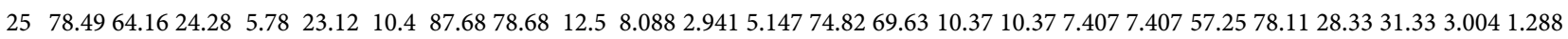
2672.5863 .6917 .884 .46924 .586 .14577 .5447 .0617 .6517 .6510 .2921 .3276 .9860 .8718 .1221 .018 .69613 .0433 .0958 .2123 .8838 .818 .9558 .955 $2730.8118 .976 .897 \quad 8.0465 .1725 .74765 .9425 .3721 .6417 .9111 .9426 .1263 .3135 .5120 .2926 .8113 .7716 .67 \quad 9.5 \quad 18.4221 .0547 .375 .26328 .95$ $28 \quad 42.1626 .4 \quad 14.61 \quad 7.8656 .742 \quad 6.18 \quad 57.9724 .4419 .2619 .265 .926 \quad 16.3 \quad 63.3131 .8818 .8426 .8114 .4913 .7722 .7229 .3532 .6145 .656 .5229 .783$ $29 \quad 40 \quad 25.7 \quad 9.4976 .14514 .534 .46974 .64 \quad 30.6 \quad 26.8724 .63 \quad 8.95517 .1664 .7534 .0617 .3928 .2615 .9410 .1430 .0225 .6238 .8439 .673 .3069 .917$

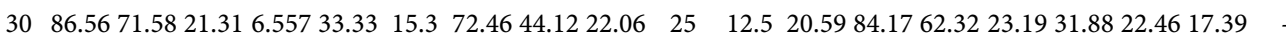

Ave. 69.0950 .7719 .267 .57521 .7210 .9578 .9648 .4627 .9218 .18 10.26 15.32 75.71 $56.6 \quad 19.7821 .7711 .5610 .2149 .5750 .6248 .1640 .815 .0415 .989$

1) A: Immediate family, B: Acquaintance in neighbor, C: Acquaintance outside neighbor, D: Organization in neighbor, E: Organization outside neighbor; 2) Ave: average from 1 to 30 . 
Table 10. Correlation between happiness and demographical status.

\begin{tabular}{|c|c|c|c|c|c|c|c|c|c|c|c|c|c|c|c|}
\hline & DK & & SE & & FI & & $\mathrm{CH}$ & & BT & & ID & & SG & JP & \\
\hline gender & 0.11 & & -0.02 & & 0.00 & & 0.05 & & -0.04 & & 0.03 & & 0.01 & 0.15 & ** \\
\hline age & -0.03 & & 0.16 & * & 0.15 & * & 0.06 & & 0.30 & $* * *$ & 0.02 & & 0.05 & - & - \\
\hline partnership & 0.07 & & 0.18 & $* *$ & 0.14 & * & 0.14 & * & 0.04 & & 0.17 & * & 0.04 & - & - \\
\hline marride & 0.08 & & 0.24 & $* * *$ & 0.16 & * & 0.16 & $* *$ & 0.18 & $* *$ & 0.1 & & 0.04 & - & - \\
\hline income & 0.07 & & 0.2 & $* *$ & 0.28 & $* * *$ & 0.24 & $* * *$ & 0.01 & & -0.03 & & 0.11 & - & - \\
\hline education & - & & - & & - & & - & & -0.16 & $* *$ & - & & - & - & - \\
\hline education' & -0.05 & & 0.03 & & 0.03 & & 0.11 & & -0.11 & & -0.00 & & 0.04 & - & - \\
\hline education" & -0.03 & & 0.10 & & -0.03 & & 0.08 & & 0.06 & & 0.2 & $* *$ & -0.01 & - & - \\
\hline education"' & 0.01 & & 0.08 & & -0.06 & & 0.03 & & -0.03 & & 0.1 & & 0.03 & - & - \\
\hline religion & 0.09 & & 0.02 & & 0.10 & & 0.01 & & - & & - & & 0.08 & - & - \\
\hline Protestant & 0.12 & * & 0.12 & & 0.20 & $* *$ & 0.07 & & - & & -0.01 & & 0.02 & - & - \\
\hline Catholic & - & & - & & - & & -0.12 & & - & & - & & -0.03 & - & - \\
\hline Bhuddism & - & & - & & - & & - & & 0.14 & * & - & & 0.09 & - & - \\
\hline Muslim & - & & - & & - & & - & & - & & -0.01 & & 0.05 & - & - \\
\hline
\end{tabular}

$1)^{* * *}$ significant with $1 \%,{ }^{* *}$ significant with $5 \%$, and ${ }^{*}$ significant with $10 \% ; 2$ ) “-“: no appropriate question or lack of enough sample.

receive it). Surprisingly, this factor had a negative correlation with happiness. The second line means secondary or junior high school, the third line means high school, and the fourth is bachelor's degree. Education did not have a strong correlation with happiness except in Indonesia.

For religion, both Protestant and Buddhist had positive correlations with happiness in Denmark and Finland (the former) and in Bhutan (the latter), respectively. Being Protestant had positive correlations with happiness in Denmark and Finland, and being Buddhist had positive correlations with happiness in Bhutan. The other countries did not show a correlation or did not have enough respondents who believed in a particular religion.

Table 11 shows the correlation between happiness and the questions on organization membership. Number 1 represents the performance of an organization on a scale from 0 to 5 . Number 2 is the performance of the respondents in the organization, also on a scale from 0 to 5 . Number 3 represents whether the respondents were liked by other people in the organization or not. The answer options were "Definitely yes", "Maybe yes", "Maybe no", and "Definitely no". Because most of the answers were the first two, "Definitely yes" was coded "1" and "Maybe yes" as " 0 ". Number 4 concerns whether the respondents liked other people in the organization or not. The answer options were "Yes", "Basically yes", "Basically no", and "No". Also in this question, "Yes" was coded "1" and "Basically Yes" was coded " 0 ". Number 5 asked whether respondents spend their time outside of the organization or not. Answer option is "Yes, frequently", "Yes but sometimes", "Only a few times", and "Never". In this question, the first two 
Table 11. Correlation between happiness and subjective evaluation for the organization.

\begin{tabular}{|c|c|c|c|c|c|c|c|c|c|c|c|c|c|c|}
\hline \multirow[b]{2}{*}{1} & \multicolumn{2}{|c|}{ DK } & \multicolumn{2}{|c|}{ SE } & \multicolumn{2}{|c|}{ FI } & \multicolumn{2}{|c|}{$\mathrm{CH}$} & \multicolumn{2}{|c|}{ BT } & \multicolumn{2}{|c|}{ ID } & \multicolumn{2}{|c|}{ SG } \\
\hline & 0.21 & $* * *$ & 0.28 & $* * *$ & 0.31 & $* * *$ & -0.01 & * & 0.56 & $* * *$ & 0.30 & $* * *$ & 0.37 & $* * *$ \\
\hline 2 & 0.20 & $* * *$ & 0.22 & $* * *$ & 0.18 & $* * *$ & 0.20 & $* *$ & 0.59 & $* * *$ & 0.01 & $* *$ & 0.12 & \\
\hline 3 & 0.1 & & 0.13 & & 0.26 & $* * *$ & 0.16 & $* *$ & 0.43 & $* * *$ & 0.27 & & 0.11 & \\
\hline 4 & 0.1 & & 0.26 & $* * *$ & 0.25 & $* * *$ & 0.10 & & 0.28 & $* * *$ & 0.49 & & 0.11 & \\
\hline 5 & 0.23 & $* * *$ & 0.20 & $* * *$ & 0.14 & & 0.12 & & 0.23 & $* * *$ & 0.63 & & 0.19 & $* *$ \\
\hline 6 & 0.3 & $* * *$ & 0.11 & & 0.25 & $* * *$ & 0.03 & & 0.28 & $* * *$ & 0.08 & * & 0.17 & $* *$ \\
\hline
\end{tabular}

1) ${ }^{* * *}$ significant with $1 \%,{ }^{* *}$ significant with $5 \%$, and ${ }^{*}$ significant with $10 \%$; 2) Number 1: performance of organization from 0 to 5 scale, Number 2: performance of respondents in the organization also from 0 to 5 scale, Number 3: whether the respondent is liked by other people in the organization or not, Number 4: whether respondent like other people in the organization or not. Number 5: whether respondent spends their time outside of the organization or not, Number 6: whether respondent discusses important things with the persons in the organization. Detail explanations of answers option are mentioned in results.

positive answers were coded " 1 " and the others were "0". Number 6 represents whether the respondents discussed important things with other persons in the organization. The answer options and coding for dummy were the same as for the question number 5. Because the Japanese data set did not have these questions, the table includes only seven countries. In all the countries surveyed, except for Switzerland, the question number 2, respondents' performance in their organizations proved significant with happiness. And all these questions showed certain significant correlations in the case of Bhutan.

Table 12 shows the correlation between happiness and number of people in the respondent's circle. Four categories were identified as close friends, friends, acquaintances, and friends on Facebook. Before the calculation, outliers and ambiguous responses were excluded. In the Japanese dataset, a similar question only about "acquaintances" was found, but the other questions were not. The number of close friends or friends correlated with happiness in Denmark, Finland, Switzerland, and Bhutan. Meanwhile, the numbers of acquaintances or friends on Facebook correlated with happiness in Finland, Singapore, and Japan. None of the variables were not correlated to happiness in Sweden or Indonesia.

\section{Discussion}

\subsection{General Relationship between Happiness and SC}

As shown in Table 6, only Denmark, Finland, Singapore, and Japan showed a correlation between happiness and SC. These countries had a correlation between the total amount of resources and happiness due to the diversity of networks; see Table 12 .

The number of acquaintances (and Facebook friends) had a positive correlation with happiness in Finland, Singapore, and Japan. If one regards these two values as proxies of diversity of human network, the results make sense. Because knowing various kinds of people is deemed important in Finland and Singapore, happiness correlated with SC-i.e., total amount of resources. 
Table 12. Correlation between happiness and numbers of surrounding people.

\begin{tabular}{|c|c|c|c|c|c|c|c|c|c|c|c|c|c|c|}
\hline \multirow[b]{2}{*}{ close friends } & \multicolumn{2}{|c|}{ DK } & \multirow{2}{*}{$\begin{array}{c}\text { SE } \\
0.00\end{array}$} & \multicolumn{2}{|c|}{ FI } & \multicolumn{2}{|c|}{$\mathrm{CH}$} & \multicolumn{2}{|c|}{ BT } & \multirow{2}{*}{$\begin{array}{c}\text { ID } \\
0.07\end{array}$} & \multirow{2}{*}{$\frac{S C}{0.07}$} & & \multicolumn{2}{|c|}{ JP } \\
\hline & 0.29 & $* * *$ & & 0.30 & $* * *$ & 0.17 & ** & 0.32 & $* * *$ & & & & - & - \\
\hline friends & 0.29 & $* * *$ & 0.02 & 0.19 & $* *$ & 0.09 & & 0.17 & * & -0.03 & 0.14 & & - & - \\
\hline acquaintances & -0.01 & & -0.02 & 0.19 & ** & 0.02 & & 0.00 & & 0.06 & 0.12 & & 0.14 & $* * *$ \\
\hline friends on facebook & 0.02 & & -0.01 & 0.17 & * & 0.02 & & -0.06 & & 0.14 & 0.29 & $* * *$ & - & - \\
\hline
\end{tabular}

$1)^{* * *}$ significant with $1 \%,{ }^{* *}$ significant with $5 \%$, and ${ }^{*}$ significant with $10 \%$.

One hypothesis in Denmark with correlation between happiness and SC lies in the Danish carrier development benefited from SC. In general, knowing various kinds of people is useful for one's career, and Danish people especially prioritize having successful careers (this will be explained later). Unlike Denmark, others such as Sweden, Switzerland, Bhutan, and Indonesia did not show similar or little correlation, observed from Figure 1. Although total resources increased with happiness, they decreased again after a certain point, except for Denmark. Regarding Finland, Singapore, and Japan, the degree of decrease in SC with an increase in happiness was relatively small. Still, a correlation existed in those countries. However, in other countries, the degree of the decrease of SC was relatively bigger. That is why some countries did not show a correlation and even the other countries showed very small correlations.

The observed inverse U-shape curves in most of the countries in Figure 1 can be explainable in the used measurement method. In Figure 1 and Table 6, SC is calculated by just a sum of total resources. This number indicates the diversity of possession of resources. Matsumoto \& Maeno (2010) revealed that having closed and close networks contributed to SWB more than being connected with various kinds of people. The sum of points generated by RG applied in our paper was close to the context of the latter. That is why SC in this analysis is not correlated with happiness in most of the countries. However, why is Denmark an exception? This can be explained by the cultural mindset (see Table 8). There was a significant difference in happiness between people who had the resource (17) "writes a recommendation letter for you in job hunting or in career changes" and people who lacked it. Only Denmark in Europe showed carrier-attached tendency. Although Denmark has a well-developed economy and its social security has a high reputation, still Danish people pursue careers. Because of progressive taxation, their income disparity is small. The interview data indicated that the Danish respondents prioritized choosing the job that they really wanted or that had a big impact on society. Thus, although they did not have to care about money, career development was important for their happiness, and to be connected with various kinds of people is important to realize that.

\subsection{Classification of Resources and International Comparison}

This section discusses the average acquisition rates for the six groups of resources divided by cluster analysis. As already mentioned, the Japanese data 
were excluded before the cluster analysis.

As a whole, the acquisition rates of "Diversity of personal connections in academy, law, and medical areas" and "Diversity of personal connections in politics and media" were lower than those of other clusters. One hypothesis for this is knowledge. Most of these resources require special expertise, while resources in "Economic support and career" and "Raising children and health of children or parents" can be provided without expertise. Therefore, limited numbers of respondents have expertise to reply "Diversity of personal connections in academy, law, and medical areas" and "Diversity of personal connections in politics and media", resulted in the low average acquisition rates of resources in these clusters. Also, the acquisition rates of resources in the "Technical support" cluster were scattered more than those in other clusters. The acquisition rate of "Technical support" in Europe was high, but that in Asia was low. It is understandable that the rate in Bhutan, the most undeveloped country among the target countries, was the lowest. However, the lower acquisition rate in Singapore compared to Indonesia was unpredictable. The target of this survey included both rich and poor people like foreigners with work permits in Singapore. Hence, even though Singapore as a whole has a high standard for technological level, the social disparity between poor and rich has resulted in people lacking access to these resources. On the other hand, people in Indonesia relatively maintain human connections unrelated to social class, Muslim networks and neighborhood relationships, resulted in high accessibility to the resources regardless of their socioeconomic status.

Bhutan and Singapore showed special characteristics of the acquisition rate of resources in each cluster. In Bhutan, the acquisition rates of resources in "Diversity of personal connections in academy, law, and medical areas" and "Technical support" were lower than those of other resources. As already mentioned, the level of development is the lowest in Bhutan. Therefore, the percentage of people who can provide these resources is low. On the other hand, the acquisition rates of resources in "Raising children and health of children or parents", "Diversity of personal connections in politics and media", and "Other" were relatively high. On one hand, "Raising children and health of children or parents" and "Other" had high acquisition rates because these areas do not require special expertise. On the other hand, the rate for "Diversity of personal connections in politics and media" is thought to be because of closeness with government or media caused by the limited population. Also, because TV is becoming popular, people may be trying to connect with these resources more. That is why the resources are more accessible in Bhutan.

In Singapore, the acquisition rates of resources in "technical support" are lower than for other resources. As already discussed, this is thought to be because of social disparities. On the other hand, acquisition rates of resources in "Diversity of personal connections in politics and media" are high. The results for (13) in Table 7 "introduces lawmakers and local government (municipalities) employees to you (or introduces acquaintances to you)" may be explainable 
because all the contact information for civil servants is open to the public in Singapore, and official citizens can be connected with such people easily. Regarding (15) "introduces you to local media (e.g., televisions station, radio stations, newspapers, and publishers)", although it is not clear why accessibility of media is good in Singapore, the public perception of media is good in general. This social background might have affected the results.

\subsection{Utility of SC's Effect on Happiness}

To identify the utility of SC's effect on happiness, chi-square tests were performed. As Table 8 shows, there were common characteristics among the target countries. While each country had different tendencies in which important resources were needed for individuals to feel happy, three types of resources emerged as common factors. First, mental support resources (e.g., (7) "mutually shares private news with each other" and (6) "mutually knows each other's families well") were important in most of the countries. These resources tended to be family members. Although it is easy to imagine such resources would be important to make people happy, they were not significant in Indonesia nor in Sweden. One reason for this may be Indonesia's religious culture. In Indonesia, all the respondents reported that they belonged to a religious group. The majority was Muslim. As such, their lifestyle would be strongly affected by Muslim culture, in which people usually help each other. For example, the interviews revealed that when their family or friends needed money, they easily lent and helped one another. They tended to be open-minded and helpful. Thus, having such resources was not special for them and not essential to determine their happiness level. The acquisition rate of these resources exceeded 90\% in Indonesia. In the case of Sweden, there was no significant difference between people who had and did not have these resources. This is thought to be caused by the small number of total respondents.

Second, resources useful to improving leisure quality (e.g., (12) "enjoys a hobby or physical activities with you" and (16) "tells you about shops dealing with goods in high quality or less expensive") were deemed important in making people happy. As Table 7 shows, these resources, along with the first two, were in the same group. These two resources (i.e., (12) (16)) were found to be significant not only in Europe, which is known for prioritizing work-life balance, but also in Asia. As Table 6 shows, Singapore had the lowest happiness level among the seven countries except for Japan. In the interviews in Singapore, the competitive working culture was mentioned as a factor for being "unhappy". Having more time and human resources for leisure might be important elements for raising the happiness level in Singapore.

Third, having the resource (17) "writes a recommendation letter for you in job hunting or in career changes" was essential for happiness in Denmark, Indonesia, Singapore, and Japan. Specifically in Denmark, people are expected to make their dreams come true and pursue their ideal job as part of the national culture. To achieve these goals, resources for better careers tend to be important, and 
citizens do not have to worry about their basic needs, which are supported by the government. In the case of Singapore, their economy's position at the highest level in Southeast Asia has fostered them to maintain their economic competitiveness, even further drive them in a competitive working culture. To keep growing, they have to be competitive, and each Singaporean is expected to work hard. In Japan, people often lack time outside of work and are said to tend not to care for doing different things with others in general. Therefore, having people to introduce them to an employer when they might lose their job is essential to be happy. Thus, the results are explainable for Denmark, Singapore, and Japan. In Indonesia, the income disparity is increasing as economic growth develops rapidly. The career market is still unequal compared with the other target countries. Under such social conditions, to have resources who help with job-hunting is essential to land a good job and feel happy.

\section{Conclusion}

The present work has three major findings. First, happiness is correlated with SC in Denmark, Finland, Singapore, and Japan, whereas non-significant correlations were found for Sweden, Switzerland, Bhutan, and Indonesia. Our hypothesis to explain this finding is utility. Countries that prioritize human connections for business as SC utility are thought to have a correlation between happiness and total number of resources given that various kinds of human networks are effective for career advancement. The correlation between happiness and number of acquaintances/Facebook friends also supports this interpretation.

Second, the acquisition rates of six kinds of resources were compared. As a whole, the acquisition rates of resources for "Diversity of personal connections in academy, law, and medical areas", and "Diversity of personal connections in politics and media" were lower than for other kinds of resources meanwhile, that of "Technical support" differed by country, caused by the national levels of development and culture. Bhutan and Singapore showed other unique tendencies concerning resources balance.

Third, when it came to each resource, resources for mental support, for spending leisure together, and for career were important to happiness in most countries. Regarding mental support, although it is easy to imagine its effect on happiness, no correlations were found in Indonesia. The reason is thought to be the Islamic culture of readily helping other people. Meanwhile, leisure raises happiness in East Asian countries, which tend to have serious hard-working cultures, too. Promoting work-life balance can be important to raise their happiness levels. Concerning careers, such resources were significant in the three Asian countries and Denmark, which promotes self-actualization.

In this study, the utility of SC's effect on happiness was explored in various countries that have different characteristics with respect to happiness level, economic condition, education, religion, and culture. Therefore, the insights from this paper can be useful for SC management in not only the target countries but also other countries with similar characteristics. 
Future studies should overcome the statistical uncertainty caused by the limited sample size and ambiguity of answers caused by translating questionnaire sheet for RG. Further, because the resources that explain SC depend on country, culture, religion, and more, it would be useful to develop a careful definition of universal resources.

\section{Acknowledgements}

The authors express deep appreciations to those who supported our surveys in the countries; Prof. Christian Bjørnskov in Denmark, Prof. Fredrik Carlsson in Sweden, Prof. Alois Stutzer and Prof. Kachi Aya in Switzerland, Prof. Pekka Neittaanmäki and Prof. Chihiro Watanabe in Finland, Prof. Pandji Prawisudha in Indonesia, and Dr. Victor Nian in Singapore.

\section{Conflicts of Interest}

The authors declare no conflicts of interest regarding the publication of this paper.

\section{References}

Bjørnskov, C. (2008). Social Capital and Happiness in the United States. Applied Research Quality Life, 3, 43-62. https://doi.org/10.1007/s11482-008-9046-6

Bjørnskov, C., \& Sønderskov, K. M. (2013). Is Social Capital a Good Concept? Social Indicators Research, 114, 1225-1242. https://doi.org/10.1007/s11205-012-0199-1

Bjørnskov, C., Dreher, A., \& Fischer, J. A. V. (2008a). Cross-Country Determinants of Life Satisfaction: Exploring Different Determinants across Groups in Society. Social Choice and Welfare, 30, 119-173. https://doi.org/10.1007/s00355-007-0225-4

Bjørnskov, C., Dreher, A., \& Fischer, J. A. V. (2008b). Formal Institutions and Subjective Well-Being; Revisiting the Cross-Country Evidence (p. 192). KOF Working Papers. https://doi.org/10.2139/ssrn.1121283

Blanchflower, D. G., \& Oswald, A. J. (2008). Is Well-Being U-Shaped over the Life Cycle? Social Science \& Medicine, 66, 1733-1749. https://doi.org/10.1016/j.socscimed.2008.01.030

Diener, E., Gohm, C. L., Suh, E. M., \& Oishi, S. (2000). Similarity of the Relations between Marital Status and Subjective Well-Being across Culture. Journal of Cross-Cultural Psychology, 31, 419-436. https://doi.org/10.1177/0022022100031004001

Frey, B. S., \& Stutzer, A. (2002). Happiness \& Economics. Princeton, NJ and Oxford: Princeton University Press.

Frey, B. S., \& Stutzer, A. (1999). Measuring Preferences by Subjective Well-Being. Measuring Preferences, 155, 755-778.

Frey, B. S., \& Stutzer, A. (2013). What Can Economists Learn from Happiness Research? In B. S. Frey, \& A. Stutzer (Eds.), Recent Developments in the Economics of Happiness (pp. 3-36). Glos: Edward Elgar Publishing Limited. https://doi.org/10.4337/9781784710552

Greve, B. (2010). Happiness and Social Policy in Europe (pp. 136-144). Glos: Edward Elgar Publishing. https://doi.org/10.4337/9781781000731

Helliwell, J., Layard, R., \& Sachs, J. (2017). World Happiness Report 2017. New York: Sustainable Development Solutions Network. 
Huppert, F. A., Marks, N., Clark, A., Siegrist, J., Stutzer, A., Vittersø, J., \& Wahrendorf, M. (2009). Measuring Well-Being across Europe: Description of the ESS Well-Being Module and Preliminary Findings. Social Indicators Research, 91, 301-305. https://doi.org/10.1007/s11205-008-9346-0

Inglehart, R. (1990). Culture Shift in Advanced Industrial Democracies. Princeton, NJ: Princeton University Press. https://doi.org/10.1515/9780691186740

Kurishima, H., Sato, S., Kurasaka, H., \& Matsuhashi, K. (2015). Correlation Analysis with the Measurement of the Residents' Social Capital by Resource Generator and Evaluation of Community: A Case Study of Ichihara City. Journal of Japan Society of Civil Engineers, 71, 91-98. https://doi.org/10.2208/jscejer.71.II_91

Lachman, M. E., \& Weaver, S. L. (1998). The Sense of Control as a Moderator of Social Class Differences in Health. Journal of Personality and Social Psychology, 74, 763-773. https://doi.org/10.1037/0022-3514.74.3.763

Matsumoto, N., \& Maeno, T. (2010). What Affect Subjective Well-Being in Interpersonal Relation Network? Japanese Journal of Interpersonal and Social Psychology, 10, 155-161.

OECD (2011). How's Life? Measuring Well-Being. Paris: OECD Publishing.

Seidlitz, L., \& Diener, E. (1993). Memory for Positive versus Negative Life Events: Theories for the Differences between Happy and Unhappy Persons. Journal of Personality and Social Psychology, 64, 654-664. https://doi.org/10.1037/0022-3514.64.4.654

Stiglitz, J. E., Sen, A., \& Fitoussi, J. P. (2009). Report by the Commission on the Measurement of Economic Performance and Social Progress (291 p.).

Tanaka, S., Kurishima, H., Nakamura, A., \& Tokimatsu, K. (2017). Characteristics of Social Capital in Tateyama City, Chiba. Journal of Environmental Information Science, 31, 59-64.

Tachibanaki, T., \& Sakoda, S. (2016). Comparative Study of Happiness and Inequality in Five Industrialized. In T. Tachibanaki (Ed.), Advances in Happiness Research (pp. 97-118). Berlin: Springer. https://doi.org/10.1007/978-4-431-55753-1_7

Tsuda, M., Hara, M., Nemoto, Y., \& Nakamura, J. (2006). Evaluation for Degree of Sustainability about ICT Services-Development from Environment to Society. NTT Technology Journal, 18, 28-31.

Van Der Gaag, M., \& Snijders, T. A. B. (2005). The Resource Generator: Social Capital Quantification with Concrete Items. Social Network, 27, 1-29. https://doi.org/10.1016/j.socnet.2004.10.001

Watanabe, C., Naveed, K., \& Neittaanmäki, P. (2015). Dependency on Un-Captured GDP as a Source of Resilience beyond Economic Value in Countries with Advanced ICT Infrastructure: Similarities and Disparities between Finland and Singapore. Technology in Society, 42, 104-122. https://doi.org/10.1016/j.techsoc.2015.04.003

Webber, M. P., \& Huxley, P. J. (2007). Measuring Access to Social Capital: The Validity and Reliability of the Resource Generator-UK and Its Association with Common Mental Disorder. Social Science \&Medicine, 65, 481-492.

https://doi.org/10.1016/j.socscimed.2007.03.030

White, A. G. (2006). A Global Projection of Subjective Well-Being: A Challenge to Positive Psychology? Psychtalk, 56, 17-20. 